\title{
Defect Persuade Paramagnetic Properties of Nickel Doped ZnS Nanocrystals and Identification of Structural, Optical, Local Atomic Structure
}

\section{Soumendra Ghorai}

Banaras Hindu University Faculty of Science

Dibyendu Bhattacharyya

Bhabha Atomic Research Centre

Nirmalendu Patra

Bhabha Atomic Research Centre

Shambhu Nath Jha

Bhabha Atomic Research Centre

Anup K Ghosh ( $\sim$ akghosh@bhu.ac.in )

Banaras Hindu University https://orcid.org/0000-0003-3601-8651

\section{Research Article}

Keywords: Nanocrystals, Paramagnetism, X-ray absorption spectroscopy, Photoluminescence

Posted Date: February 19th, 2021

DOI: https://doi.org/10.21203/rs.3.rs-216850/v1

License: (c) (1) This work is licensed under a Creative Commons Attribution 4.0 International License.

Read Full License 


\title{
Defect persuade paramagnetic properties of nickel doped $\mathrm{ZnS}$ nanocrystals and identification of structural, optical, local atomic structure
}

Soumendra Ghorai ${ }^{\mathrm{a}}$, Dibyendu Bhattacharyya ${ }^{\mathrm{b}}$, Nirmalendu Patra ${ }^{\mathrm{b}}$, Shambhu Nath Jha ${ }^{\mathrm{b}}$, Anup K. Ghosh ${ }^{\mathrm{a}, *}$

${ }^{a}$ Department of Physics, Institute of Science, Banaras Hindu University,Varanasi-221005,India.

${ }^{b}$ Atomic \& Molecular Physics Division, Bhabha Atomic Research Centre,Mumbai-400085,India.

*corresponding author: akghosh@bhu.ac.in

\begin{abstract}
We have methodically investigated the structural, spectroscopic, local atomic structure and magnetic properties of aquatic $\mathrm{Zn}_{1-\mathrm{x}} \mathrm{Ni}_{\mathrm{x}} \mathrm{S}(0 \leq \mathrm{x} \leq 0.04)$ nanocrystals. The structural study of synthesized samples are observed by X-ray diffraction datas with Rietveld refinement. Proficient decrease of lattice parameters and inter-planar spacing are determined on $\mathrm{Zn}_{1-x} \mathrm{Ni}_{\mathrm{x}} \mathrm{S}$ nanocrystals. The nanocrystalline microstructure is identified by high resolution transmission electron microscopy. The sphalerite morphology of doped samples are observed by scanning electron microscopy. Shrinkage of energy band gap is observed for doped nanocrystals. Defect formation due to doping of Ni ion is observed by photoluminescence spectroscopy with cyan color emission. X-ray absorption spectroscopy is employed for identification of local structures surrounding of $\mathrm{Zn}$ and $\mathrm{Ni}$ sites of $\mathrm{Zn}_{1-\mathrm{x}} \mathrm{Ni}_{\mathrm{x}} \mathrm{S}$ nanocrystals. Extended X-ray absorption fine structure investigation evidenced the existence of nanocluster within the lattice of $\mathrm{Zn}_{1-\mathrm{x}} \mathrm{Ni}_{\mathrm{x}} \mathrm{S}$ nanocrystals. X-ray absorption near edge structure studies confirmed incorporation of $\mathrm{Ni}^{2+}$ in $\mathrm{ZnS}$ lattice of $\mathrm{Zn}_{1-\mathrm{x}} \mathrm{Ni}_{\mathrm{x}} \mathrm{S}$ nanocrystals. The single pre-edge feature at $\mathrm{Ni}$ K-edge is not relying on concentration of $\mathrm{Ni}$ dopant in $\mathrm{Zn}_{1-\mathrm{x}} \mathrm{Ni}_{\mathrm{x}} \mathrm{S}$ nanocrystals. The presence of interstitial $\mathrm{Ni}$ is identified by significant fraction of $\mathrm{Ni}-\mathrm{Ni}$ scattering paths on doped samples. $\mathrm{Zn}_{1-}$ ${ }_{x} \mathrm{Ni}_{\mathrm{x}} \mathrm{S}$ nanocrystals exhibit defect persuaded paramagnetism at room temperature.
\end{abstract}

Key Words: Nanocrystals; Paramagnetism; X-ray absorption spectroscopy; Photoluminescence

\section{Introduction}

Sulfide doped diluted magnetic semiconductors are important because of their novel potential applications in electronics and optoelectronics [1]. Currently, metal sulfides have attracted more attention in photocatalysis and antimicrobial activities because of their suitable band gap, catalytic function and toxic nature [1]. Zinc sulfide $(\mathrm{ZnS})$ is an important II-VI compound semiconductor which is less toxic in nature and has wide potential applications in nonlinear optical devices, light emitting diodes and solar cells [2]. Doping with transition metal ions as well as rare earth metal ions are renowned pathway to achieve control on the properties of nano scale materials 
[2]. Nano-dimensional transition metal doped $\mathrm{ZnS}$ is found to exhibit excellent optical and optoelectronic properties that are remarkably different from the bulk [3,4], making it a versatile building block for nanoscale electronic and photonic devices. Nanocrystals with zero dimension have been synthesized by different technique like hydrothermal method $[1,3,5,6]$, wet chemical precipitation method [4,7], micro wave assisted chemical synthesis etc. by transitional metal doped $\mathrm{ZnS}$ [8]. Dilute magnetic semiconductors (DMS) having room temperature magnetism which attracted researcher because of the exchange interactions between the spins of the dopant atoms and the carriers on semiconductor host. In this work, nickel (Ni) doped ZnS nanocrystals are synthesized by high temperature aqueous synthesis method. Among the transition metals nickel (Ni) is chosen as the dopant on $\mathrm{ZnS}$ nanocrystals because of almost similar ionic radius and substitutes on $\mathrm{Zn}^{2+}$ lattice easily. Ni has magnetic moment and theoretical approach of magnetism in nickel based diluted semiconductors reported elsewhere [9-11]. Kumar et al. have shown intrinsic nature of magnetism for $\mathrm{Ni}$ doping on $\mathrm{ZnS}$ nanoparticles [7]. Saika et al. suggested that ferromagnetism in Ni doped $\mathrm{ZnS}$ samples are results of exchange interaction between localized ' $d$ ' spins on $\mathrm{Ni}$ ions and free delocalized carries [12]. The half metallic ferromagnetism on Ni doped $\mathrm{ZnS}$ nanoparticles is reported by Akhtar et al. [13]. Schulz et al. have investigated paramagnetic resonance of Ni doped ZnS crystals [14].

The dependence on atomic number of doped manganese, iron and copper ions, which describe the atomic position of hybridized band energy of transitional metal ' $3 d$ ' shell and ' $3 p$ ' shell of sulfur anti bonding states in $\mathrm{Zn}_{1-\mathrm{X}} \mathrm{Ni}_{\mathrm{X}} \mathrm{S}(\mathrm{M}=\mathrm{Mn}, \mathrm{Fe}, \mathrm{Co})$ alloys are reported by Pong et al. [15]. The report of Lawniczak-Jablonska et al. have showed that lower order effect in second nearest shell due to doping of high concentration cation in $\mathrm{Zn}_{1-\mathrm{X}} \mathrm{Ni}_{\mathrm{X}} \mathrm{S}$ [16]. They observed only variation in the ' $p$ ' state localization but it has limitation for low concentration cation substitution. [16]. In our report, the local electronic structure of $\mathrm{Zn}_{1-\mathrm{X}} \mathrm{Ni}_{\mathrm{X}} \mathrm{S}$ surrounding $\mathrm{Zn}$ and $\mathrm{Ni}$ sites are observed by utilizing synchrotron based X-ray absorption spectroscopy (XAS) which comprise both 'extended X-ray absorption fine structure spectroscopy' (EXAFS) and 'X-ray absorption near edge spectroscopy' (XANES) measurements. The structural information is correlated with X-ray diffraction (XRD) and transmission electron microscopy (TEM) measurements. Scanning electron microscopy demonstrates morphology of nanocrystals. Spectroscopic properties of nanocrystals are observed by 'Ultra-violet visible (UV-visible) spectroscopy' and 'photoluminescence spectroscopy'. Magnetic properties are demonstrated by 'SQUID' ('superconducting quantum interference device magnetometer'). $\mathrm{Zn}_{1-\mathrm{x}} \mathrm{Ni}_{\mathrm{X}} \mathrm{S}$ nanocrystals explicated with amalgamation of paramagnetic demeanor and cyan luminescence properties may be utilized for practical device use. In this work the Ni doped $\mathrm{ZnS}$ nanocrystals have been prepared by varying the composition of $\mathrm{Zn}$ and $\mathrm{Ni}$ and we concentrate on the correlation of structural, local atomic structure, spectroscopic and magnetic properties of the samples. 


\section{Experimental section}

\subsection{Method of sample preparation}

$\mathrm{Zn}_{1-\mathrm{x}} \mathrm{Ni}_{\mathrm{X}} \mathrm{S}(0 \leq x \leq 0.04)$ nanocrystals ( $\left.\mathrm{NCs}\right)$ samples are prepared by modified aquasynthetic method and labeled as $\mathrm{Ni}_{0}, \mathrm{Ni}_{0.5}, \mathrm{Ni}_{1}, \mathrm{Ni}_{2}$ and $\mathrm{Ni}_{4}$ for distinctive $\mathrm{Ni}$ dopant on $\mathrm{ZnS}, \mathrm{x}=0$, $0.5 \%, 1 \%, 2 \%$ and $4 \%$ receptively. All chemicals were reagent grade and used as obtained. The hydrophilic polymer PVP (polyvinyl pyrolodine, K-30) was used as a stabilizer to synthesize waterdispersive nanocrystals (NCs). To discuss the whole chemical reaction procedure shortly, four mmol zinc acetate, $6 \times 10^{-3} \mathrm{mmol}$ PVP and appropriate amount (x mmol) of nickel acetate were dissolved in $100 \mathrm{ml}$ distilled water. The solution contained flask was stirred for one hour at room temperature. Afterward, the flask was moved to a hot plate. The temperature of hot plate retained at $473 \mathrm{~K}$. Thereafter, $100 \mathrm{ml}$ solution of sodium sulfide was dripped into the flask under vigorous stirring. In this condition, the reaction was continued to two hours. After that, temperature of the mixed solution was steadily cooled down at laboratory condition. Washing procedure of mixed polymers was carried out by incessant re-dispersion and centrifugation ( 10000 rotation per minute for 25 minutes). This processes were performed utilizing with distilled water and with ethanol. Thereafter, prepared precipitate were placided and preserved by removing moisture on vacuum oven at $323 \mathrm{~K}$ for 14 hours. The white $\left(\mathrm{Ni}_{0}\right)$ and slight yellowish $(\mathrm{x}=0.005$ to 0.04$)$ powder of $\mathrm{Ni}$ doped zinc sulfide NCs were came into possession of grinding the dried precipitate. The exothermic reaction can be expressed as

$$
(1-\mathrm{x}) \mathrm{Zn}\left(\mathrm{CH}_{3} \mathrm{COO}\right)_{2}+\mathrm{x} \mathrm{Ni}\left(\mathrm{CH}_{3} \mathrm{COO}\right)_{2}+\mathrm{Na}_{2} \mathrm{~S} \stackrel{\text { 473K, } \mathbf{P V P}}{\longrightarrow} \mathrm{Zn}_{1-\mathrm{x}} \mathrm{Ni}_{\mathrm{x}} \mathrm{S}+2 \mathrm{CH}_{3} \mathrm{COO}^{-} \mathrm{Na}^{+}
$$

\subsection{Characterizations}

The structural parameter of the prepared nanocrystals samples were determined by a Miniflex600, Rigaku, X-ray diffractometer at room temperature over the range $20^{\circ} \leq 2 \theta \leq 80^{\circ}$ with increment step size of $0.02^{\circ}$ and scanning rate of $2^{\circ} /$ minute with $\mathrm{CuK}_{\alpha}$ radiation. Rietveld refinements were performed with 'Fullproff Suite' software [17]. The 'Technai $G^{2}$ Twin field emission transmission electron microscope' (FEI, Netherland) was utilized to observe the transmission electron microscope (TEM), high resolution TEM (HRTEM) images and selected area electron diffraction (SAED) images and the measurements were performed with fixed current of $10 \mu \mathrm{A}$. Scanning electron microscope (SEM) images were taken with 'EVO Scanning Electron Microscope MA15/18' (Zeiss, Germany)' equipped with 'energy-dispersive X-ray spectroscopy' (EDS) detector. The micro Raman system 'LABRAM-HR visible' ('Horibra Jobin Yvon', 'Model: HR800') was utilized to observe Raman spectrum. To obsolete structural distortion because of laser warming, the source was adjusted with power head of $10 \mathrm{~mW}$ and excited with $\sim 633 \mathrm{~nm}$ wavelength laser. To obtain 'Ultra Violet-Visible' (UV-visible) spectrum the 'Perkin Elmer Instrument (Lambda-25, USA)' was utilized with step size of $1 \mathrm{~nm}$ [17-18]. The room temperature photoluminescence emission experiments of the prepared samples were performed by utilizing the 'Perkin Elmer spectro-fluorometer' (Model: F35). For the 
EXAFS experiments of $\mathrm{Zn}_{1-\mathrm{X}} \mathrm{Ni}_{\mathrm{X}} \mathrm{S}$ NCs, transmission mode was employed to measure $\mathrm{Zn}$ K-edge $(9659 \mathrm{eV})$ and fluorescence mode was employed to measure Ni K-edge $(8331 \mathrm{eV})$. Necessary amount of the synthesized samples were blended accurately with cellulose powder and squeezed to obtain 10 $\mathrm{mm}$ (diameter) $\times 1 \mathrm{~mm}$ (thickness) homogenous circular pellets for obtain proper intensity at $\mathrm{K}$ edges. The pellets were compressed on narrow strip to append with sample holder [17]. The XAS experiments of $\mathrm{Zn}_{1-\mathrm{x}} \mathrm{Ni}_{\mathrm{X}} \mathrm{S} \mathrm{NCs}$ were performed at 'Raja Ramanna Centre for Advanced Technology (RRCAT), Indore, India' at the 'Energy Scanning EXAFS beam line (BL-9) at Indus-2 Synchrotron with source of $2.5 \mathrm{GeV}, 100 \mathrm{~mA}$ and with beam size of $0.5 \mathrm{~mm} \times 0.5 \mathrm{~mm}$ at room temperature' [17,19-22]. A 'superconducting quantum interference device' ('SQUID'; 'MPMS Quantum Design, Model: 1802') magnetometer was employed for magnetic experiments. The magnetic field depended $(\mathrm{M}-\mathrm{H})$ experiments are performed in the range of \pm 2 Tesla $(\approx 20000$ Oersted $)$ at $300 \mathrm{~K}$. Magnetization as function of temperature (M-T) experiments are performed with fixed magnetizing field of $1000 \mathrm{Oe}$ for $\mathrm{Ni}_{0}$ and $\mathrm{Ni}_{4}$ samples within the range of $5 \mathrm{~K}$ to $300 \mathrm{~K}$. For $\mathrm{M}-\mathrm{H}$ and M-T experiments $0.03157 \mathrm{~g}$ of $\mathrm{Ni}_{0}$ sample and $0.02167 \mathrm{~g}$ of $\mathrm{Ni}_{1}, \mathrm{Ni}_{2}$ and $\mathrm{Ni}_{4}$ samples are utilized.

\section{Results and discussion}

\subsection{X-ray diffraction}

The structural study of the prepared $\mathrm{Zn}_{1-\mathrm{X}} \mathrm{Ni}_{\mathrm{X}} \mathrm{S}(0 \leq x \leq 0.04)$ nanocrystals (NCs) are investigated by X-ray diffraction (XRD) patterns with the Rietveld refinement and demonstrated in Fig.1. The recorded diffraction peaks of prepared $\mathrm{Zn}_{1-\mathrm{X}} \mathrm{Ni}_{\mathrm{X}} \mathrm{S}$ nanocrystals (NCs) are correlative to standard Bragg position of cubic zinc sulfide (Fig.1). The decrease of lattice parameter (Fig.2a) and inter-planar spacing of (111) plane are observed (Fig. 2b) from Rietveld refinement of XRD data. The development of small sized nanocrystals of $\mathrm{Zn}_{1-\mathrm{X}} \mathrm{Ni}_{\mathrm{X}} \mathrm{S}$ samples are reason for broadened XRD patterns in comparison to its bulk correlative. It can also be seen that $\mathrm{Ni}$ substitution in $\mathrm{ZnS}$ lattice does not affect to inclusion or absence of any diffraction peak other than that of pure cubic $\mathrm{ZnS}$ manifesting absence of any impurity or secondary phase (i.e. nickel metal, $\mathrm{NiS}, \mathrm{SO}_{2}$ ) within the range of observed limit of XRD pattern for all prepared samples. However, probability for existence of any impurity peaks or nano cluster without any long range order is discussed in X-ray absorption spectroscopy section. Any significant variation in intensities of the XRD peaks of $\mathrm{ZnS}$ due to possible waning of crystallization upon $\mathrm{Ni}$ doping has not also been observed in the samples. However, little change in FWHM of main peaks are observed because of Ni ion (0.55 $⿱$ ) doping, which confirms $\mathrm{Ni}$ is entering the lattice of host material [21]. The average crystallite size estimated from the Scherrer's equation found to be $\sim 2.0 \mathrm{~nm}$ for all NCs samples [17,22]. In the present set of samples, the microstrain originate because of dislocation which precede to peak broadening. The defect formation mechanism due to $\mathrm{Ni}$ dopant in $\mathrm{ZnS}$ is identified by photoluminescence studies. 


\subsection{Scanning electron microscopy}

The surface morphology of $\mathrm{Zn}_{1-\mathrm{x}} \mathrm{Ni}_{\mathrm{X}} \mathrm{S}$ nanocrystals are verified by SEM images which shown in Fig. 3(a)-3(d). It is observed that agglomerated grains are distributed throughout the surface on $\mathrm{Zn}_{1-\mathrm{x}} \mathrm{Ni}_{\mathrm{X}} \mathrm{S}$ nanocrystals. The SEM images relate considerable agglomeration of nanocrystals with sphalerite nanocluster on the surface. The atomic percentages of $\mathrm{Ni}$ and $\mathrm{ZnS}$ in the respective $\mathrm{Ni}_{0}, \mathrm{Ni}_{1}, \mathrm{Ni}_{2}$ and $\mathrm{Ni}_{4}$ samples are estimated from the energy dispersive X-ray spectroscopy (EDS) measurements and tabulated in Table 1 .

\subsection{Transmission electron microscopy}

The transmission electron microscopy (TEM) measurements are employed to study microstructure of the prepared nanocrystals (Fig. 4). From the TEM images we observed that allocation of nano-crystallite size of $\mathrm{Ni}_{0}$ nanocrystals retains within $\sim 1.0 \mathrm{~nm}$ to $\sim 3.20 \mathrm{~nm}$ and for higher doped nanocrystals $\left(\mathrm{Ni}_{4}\right)$ it retains between $\sim 1.1 \mathrm{~nm}$ to $\sim 3.19 \mathrm{~nm}$. The TEM micrographs demonstrated that nanocrystals are rippleless on surface and tiny spherical in configuration. From the HRTEM images it is observed that interplanar spacing (111) plane of the $\mathrm{Ni}_{0} \mathrm{NCs}$ and the $\mathrm{Ni}_{4} \mathrm{NCs}$ are $0.3088 \mathrm{~nm}$ and $0.30704 \mathrm{~nm}$ respectively. The existence poly crystalline nature of nanocrystals are evidenced from HRTEM images and ring like SAED patterns.

\subsection{Raman spectroscopy}

The crystalline quality and the local structural variations on $\mathrm{Zn}_{1-\mathrm{x}} \mathrm{Ni}_{\mathrm{X}} \mathrm{S}(0 \leq x \leq 0.04)$ nanocrystals are observed with micro-Raman spectroscope characterization and demonstrated in Fig. 5. The polarization characteristics are identified by Raman spectroscopy with satisfactorily recognized indication of acoustic and optical modes [17,23]. There are two pronounced bands observed at 263 $\mathrm{cm}^{-1}$ and $347 \mathrm{~cm}^{-1}$, which are identified as transverse optical (TO) and longitudinal optical (LO) modes, respectively. It is observed that intensity of pronounced modes of doped samples are lower compared to pure nanocrystal sample. It is also identified that the local symmetry of doped nanocrystals are retain similar to the $\mathrm{Ni}_{0} \mathrm{NCs}$ sample. The present observations implied that $\mathrm{Ni}$ dopant does not influenced on the lattice structure of nanocrystals and it corroborates with the TEM observations. However, it is observed that the Raman peaks are shifted toward lower energy (Table 2) as compared to the bulk $\mathrm{ZnS}$ values [23-26], which signify quantum confinement effects on synthesized $\mathrm{Ni}_{0} \mathrm{NCs}$ and $\mathrm{Zn}_{1-\mathrm{X}} \mathrm{Ni}_{\mathrm{X}} \mathrm{S}$ NCs.

\subsection{UV-visible spectroscopy}

Fig. 6 demonstrated the 'UV-visible absorption' spectrum of the $\mathrm{Zn}_{1-\mathrm{x}} \mathrm{Ni}_{\mathrm{X}} \mathrm{S}$ NCs samples. It is observed that an absorption peak located at around $321 \mathrm{~nm}$ in $\mathrm{Ni}_{0} \mathrm{NCs}$ sample and also the energy band gap of all samples are estimated from 'Tauc plot' [27]. 'The equation $(\alpha h \gamma)^{2}=C\left(h \gamma-E_{g}\right)$ 
where, $\mathrm{h}$ is Planck's constant, $\gamma$ is the frequency of radiation, $\mathrm{C}$ is a constant and $\mathrm{E}_{\mathrm{g}}$ is the energy band gap of the material, is utilized to determine direct energy band of synthesized materials from high absorption region' [27]. The 'Beer-Lambert's relation, $\alpha=2.303 \times C / t$, where ' $t$ ' is path length of the quartz cuvette and ' $\mathrm{C}$ ' is absorbance obtained from UV-visible spectrum, is employed to evaluate the absorption coefficient ( $\alpha)^{\prime}$ [27]. There are number of exciton peaks appearing at different energies corresponding to different sized nanocrystals which overlap with another resulting into broad absorption spectra, so the size distribution is broad [28]. The red shift of absorption wavelength is observed with increase in Ni doping implying that the energy band gap of nanocrystals decreases with increase in doping concentration of $\mathrm{Zn}_{1-\mathrm{X}} \mathrm{Ni}_{\mathrm{X}} \mathrm{S}$ NCs. The decrement of band energy gap of synthesized doped nanocrystals arises because of spin exchange interaction with ' $s p$ ' and ' $d$ ' orbital of conduction and valence bands in $\mathrm{ZnS}$ and localized ' $d$ ' electrons of Ni ions [28,29]. The shrinkage of energy band gap takes place due to decrement of optical absorption band edge with higher Ni donor density along with excess charge in conduction band and strengthen the interaction potentials between $\mathrm{Ni}$ donor electrons and to the host $\mathrm{Ni}_{0} \mathrm{NCs}[30]$.

\subsection{X-ray absorption spectroscopy}

The quantitative comparison of absorption quality at the $\mathrm{Zn}$ K-edge $(9659 \mathrm{eV})$, the normalized 'X-ray absorption near edge structure' (XANES) spectrum of $\mathrm{Zn}_{1-\mathrm{X}} \mathrm{Ni}_{\mathrm{X}} \mathrm{S}$ NCs samples including the $\mathrm{Zn}$ metal foil and pure $\mathrm{ZnS}$ are performed and demonstrated in the Fig. 7.

From Fig. 7, it has been observed that the $1^{\text {st }}$ inflection point at $\mathrm{Zn} \mathrm{K-edge} \mathrm{of} \mathrm{Zn}_{1-\mathrm{X}} \mathrm{Ni}_{\mathrm{X}} \mathrm{S}$ samples similar to that of undoped $\left(\mathrm{Ni}_{0}\right)$ NCs sample. The result suggests that the oxidation state of $\mathrm{Zn}$ atoms retains unperturbed in same state +2 in prepared $\mathrm{Zn}_{1-\mathrm{X}} \mathrm{Ni}_{\mathrm{X}} \mathrm{S}$ NCs. The electronic transition from $\mathrm{Zn} 1 s$ state to $4 p$ state causes the absorption at $\mathrm{Zn} \mathrm{K}$-edge. Moreover, no pre-edge is found out because outer valence ' $d$ ' shell is fully filled. In Fig. 7, a prominent change in white line intensity is observed. The change in unoccupied electron density of states in the outer most orbital may cause such intensity variation [19-21]. From Fig. 7., it has been concluded that the structural symmetry surrounding zinc atoms exhibit similar features for $\mathrm{Zn}_{1-\mathrm{X}} \mathrm{Ni}_{\mathrm{X}} \mathrm{S}$ samples. This observation also rules out creation of zinc oxide nanocluster in $\mathrm{Zn}_{1-\mathrm{X}} \mathrm{Ni}_{\mathrm{X}} \mathrm{S}$ samples.

The local structure around the absorbing atom is obtained from the quantitative analysis of EXAFS spectra following the standard procedure [19-21]. In order to take care of the oscillations in the absorption spectra $\mu(E)$ has been converted to absorption function $\chi(E)$ defined as follows:

$$
\chi(E)=\frac{\mu(E)-\mu_{0}(E)}{\Delta \mu_{0}\left(E_{0}\right)}
$$


where, absorption edge energy is expressed as $E_{0}$, background of the bare atom expressed as $\mu_{0}\left(E_{0}\right)$ and $\Delta \mu_{0}\left(E_{0}\right)$ is expressed as the step in $\mu(E)$ value at the absorption edge. The energy dependent absorption coefficient $\chi(E)$ has been converted to the wave number dependent absorption coefficient $\chi(k)$ using the relation,

$$
K=\sqrt{\frac{2 m\left(E-E_{0}\right)}{\hbar^{2}}}
$$

where, ' $\mathrm{m}$ ' is the electron mass. $\chi(k)$ is weighted by $k^{2}$ to amplify the oscillation at high $k$ and the $\chi(k) k^{2}$ functions are fourier transformed to generate the $\chi(R) v s . R$ plots in terms of the real distances from the center of the absorbing atom. The above exercise has been done using the ATHENA subroutine of the Demeter software package [19].

Fig. 8 exhibits the $k^{2}$ weighted $\chi(k)$ spectra of the $\mathrm{Zn}_{1-\mathrm{x}} \mathrm{Ni}_{\mathrm{X}} \mathrm{S}$ samples while the phase uncorrected fourier transformed $\chi(R)$ vs. $R$ plots obtained from experimental data are exhibited in Fig. 9 where the fourier transform is carried out within a $k$ range of 2-9 $\AA^{-1}$. The first co-ordination shell exists at a distance of $2.32 \AA$ which lead to $1^{\text {st }}$ intense peak emerging within the $R$ range of 1.2 $\AA$ to $2.6 \AA$ distance in the fourier transformed $\chi(R) v s . R$ spectra at the Zn K-edge. Because of higher disorder in $2^{\text {nd }}$ co-ordination shell, no significant peak is observed after $2.5 \AA$. Subsequently to extract more quantitative information, the experimentally derived $\chi(R)$ vs. $R$ data are fitted with theoretically simulated plots. For simulation of the theoretical $\chi(R)$ vs. $R$ data pure $\mathrm{ZnS}$ structure with lattice parameter $(\mathrm{a}=5.35 \AA)$ determined from 'Rietveld refinement' is utilized and the individual atomic scattering paths are created consequently.

In this structure, the $\mathrm{Zn}$ atom placed at $(0,0,0)$ location is circumscribed by four sulfur atoms in the $1^{\text {st }}$ co-ordination shell which created a tetrahedral symmetry with an atomic scattering path of $2.32 \AA$ and also circumscribed by twelve $\mathrm{Zn}$ atoms in adjacent co-ordination sphere at an atomic scattering path of $3.78 \AA$ A. Fig. 8 . the best fit $\chi(R)$ vs. $R$ are shown along with the experimental data where fitting has been done in the $R$ range of 1 to $3 \AA$. The bond distance $(R)$ of atom to atom and Debye-Waller factor $\left(\sigma^{2}\right)$ are assorted though the co-ordination number $(\mathrm{CN})$ of each co-ordination shell retained constant during fitting procedure. The ATOMS subroutine of the Demeter software package has been used for the generation of the theoretical EXAFS spectra starting from an assumed crystallographic structure and finally fitting of experimental data with the theoretical spectra has been carried out using the ARTEMIS subroutine.

The fitted results obtained from EXAFS data at the $\mathrm{Zn}$ K-edge of $\mathrm{Zn}_{1-\mathrm{X}} \mathrm{Ni}_{\mathrm{X}} \mathrm{S}$ samples are tabulated in Table 3. It has been observed that there is no change in $1^{\text {st }}$ co-ordination shell $(\mathrm{Zn}-\mathrm{S})$ with 
increase in dopant concentration of $\mathrm{Zn}_{1-\mathrm{X}} \mathrm{Ni}_{\mathrm{X}} \mathrm{S}$ and it is similar to scattering path $(2.28 \AA)$ of $\mathrm{Ni}_{0}$ sample. So, it has been concluded that lower dopant concentration do not affect the first co-ordination shell of the $\mathrm{Zn}$ atoms though their ionic radii are similar $\left(\mathrm{Zn}^{2+}=0.60 \AA, \mathrm{Ni}^{2+}=0.55 \AA\right)$ [19-23].

The quantitative comparison of absorption quality at the Ni K-edge $(8331 \mathrm{eV})$, the normalized X-ray absorption near edge structure (XANES) spectrum of doped NCs samples including the Ni metal foil, standard $\mathrm{NiS}$, and $\mathrm{NiSO}_{4}$ are performed to obtain oxidation state of nickel ions in $\mathrm{Zn}_{1-\mathrm{X}} \mathrm{Ni}_{\mathrm{X}} \mathrm{S}$ samples and demonstrated in Fig. 10. The absorption at Ni-K edge is identical to that observed in $\mathrm{Ni}$ doped samples and that of $\mathrm{NiS}$ and $\mathrm{NiSO}_{4}$, which indicates that on the doped samples $\mathrm{Ni}$ ions have +2 oxidation state. Moreover, the absorption spectra of the samples exhibit the presence of single pre-edge feature just below the absorption edge (Fig. 11), which is a typical observation for $\mathrm{NiSO}_{4}$ sample.

Fig. 12 exhibits $k^{2}$ weighted $\chi(k)$ spectra observed at Ni K-edge of the Ni doped ZnS NCs samples. Instead of the $\mathrm{Zn}$ atom, $\mathrm{Ni}$ atom is placed as central absorbing atom to fit the experimental data at $\mathrm{Ni}-\mathrm{K}$ edge, assuming the cubic $\mathrm{ZnS}$ structure, however, the model is unable to fit the experimental data even at $1^{\text {st }}$ co-ordination shell. In Fig. 13, fourier transformed EXAFS spectra or the $\chi(R)$ vs. $R$ spectra of the $1^{\text {st }}$ co-ordination shell of $\mathrm{Ni}$ is shown. To fit experimental data by assuming $\mathrm{NiS}$ and $\mathrm{NiS}_{2}$ structures but such models are unable to fit satisfactorily. Because of the Ni-S bond length is in the range of $2.2 \AA$ so we are unable to fit $1^{\text {st }}$ peak in the $\chi(R)$ vs. $R$ plot of the $\mathrm{Ni}$ $\mathrm{K}$-edge data. Thereafter, the experimental data is fitted by assuming standard $\mathrm{NiSO}_{4}$ (hexahydrate) structure with space group (tP48) where $1^{\text {st }}$ peak of $\chi(R) v s . R$ plot located at $\sim 1.5 \AA$. In this structure $\mathrm{Ni}$ atom is circumscribed by $6 \mathrm{O}$ atoms in $1^{\text {st }}$ co-ordination shell and provides information that first intense peak exists within the $R$ range 1-2 $\AA$. Further in the phase uncorrected $\chi(R)$ vs. $R$ spectra, $2^{\text {nd }}$ co-ordination shell $(\mathrm{Ni}-\mathrm{Ni})$ arises in the range between 2 to $2.8 \AA$. The best fit theoretically simulated $\chi(R)$ vs. $R$ plots for the $\mathrm{Zn}_{1-\mathrm{x}} \mathrm{Ni}_{\mathrm{x}} \mathrm{S}$ samples assuming the above structure are also shown in Fig. 13 along with the experimental data. The results obtained from EXAFS data at the Ni K-edge of samples are tabulated in Table 4. The Table 4 exhibits that Ni-O bond length acquired from fitting the $\mathrm{Zn}_{1-\mathrm{x}} \mathrm{Ni}_{\mathrm{X}} \mathrm{S}$ nanocrystals is $\sim 1.99 \AA$ 践 which is close to that in $\mathrm{NiSO}_{4}$ sample. So it is confirmed that in $\mathrm{Zn}_{1-\mathrm{x}} \mathrm{Ni}_{\mathrm{X}} \mathrm{S}$ nanocrystals, $\mathrm{Ni}$ atoms create $\mathrm{NiSO}_{4}$ nanoclusters. It should be noted that the presence of $\mathrm{NiSO}_{4}$ nanoclusters, however could not be detected by X-ray diffraction, discussed earlier, possibly due to its low concentration and lack of long range order of this phase. 


\subsection{Photoluminescence spectroscopy}

Fig. 14 shows the room temperature photoluminescence (PL) spectrum of the undoped and $\mathrm{Zn}_{1-\mathrm{x}} \mathrm{Ni}_{\mathrm{X}} \mathrm{S} \quad(0 \leq x \leq 0.04) \mathrm{NCs}$ samples excited at wavelength $320 \mathrm{~nm}$. The band-edge emissions of the nanocrystals is observed at about $450 \mathrm{~nm}$ which suggests that the trap states emission of $\mathrm{ZnS}$ is related to native zinc vacancy [31,32]. The blue band edge emissions at around $460 \mathrm{~nm}$ and $472 \mathrm{~nm}$ in $\mathrm{Ni}_{0}$ sample may originate from $\mathrm{Zn}$ donor - S accepter pair which is correlated with the radiative recombination [18]. Such radiative recombination occurs by collision procedure of excitons. Origin of peak at $472 \mathrm{~nm}$ is due to sulfur vacancy in the undoped and $\mathrm{Ni}$ doped $\mathrm{ZnS}$ [18,32]. With increase in doping concentration of $\mathrm{Ni}$ dopant on $\mathrm{ZnS}$ NCs this peak is decreased because of defect states. A cyan emission peak has been observed in the wavelength region of $484 \mathrm{~nm}$ for all $\mathrm{Zn}_{1-\mathrm{x}} \mathrm{Ni}_{\mathrm{x}} \mathrm{S}$ NCs samples which is associated with the recombination of free charge carriers and surface defect sites of the nanocrystals.

\subsection{Magnetic properties}

The field dependent magnetization (M-H) experiments are executed to identify the magnetic characteristics of synthesized samples. The $\mathrm{Zn}_{1-\mathrm{X}} \mathrm{Ni}_{\mathrm{X}} \mathrm{S}$ samples exhibit paramagnetic behavior (Fig. 15) in comparison to the diamagnetic $\mathrm{Ni}_{0} \mathrm{NCs}$ which is verified from the magnetic property studies (inset Fig. 15) [32-33]. The paramagnetic nature may be attributed to the surface defects that can exist on the $\mathrm{Zn}_{1-\mathrm{x}} \mathrm{Ni}_{\mathrm{X}} \mathrm{S}$ samples. Because of tiny sized of nanocrystals, ratio of surface to volume exceeded considerably, so the surface defect intercede properties have assured signature in the nanomagnetism of $\mathrm{Zn}_{1-\mathrm{x}} \mathrm{Ni}_{\mathrm{X}} \mathrm{S}$ samples though the effect of small amount of $\mathrm{NiSO}_{4}$ nanoclusters in the samples, as observed from Ni-K edge XAS measurements cannot be ruled out.

The inextinguishable characteristic of M-H loop is paramagnetic, though the magnetization retained unsaturated till magnetic field of $\sim 2 \mathrm{~T}$ which an indication of little antiferromagnetic interactions in the studied system. The number of $\mathrm{Ni}$ ions is higher, hence, Ni-Ni center distance decreases which may enhance antiferromagnetic Ni-Ni interaction at room temperature, that leads to non-saturation of M-H curves of Ni dopant on $\mathrm{ZnS}$.

To find the influence of $\mathrm{Ni}$ dopant on $\mathrm{ZnS}$ lattice, the thermal variant of magnetization (M-T) with magnetic field of 1000 Oe by following a field cooled protocol is measured for both $\mathrm{Ni}_{0}$ and $\mathrm{Ni}_{4}$ NCs samples. The negative magnetization within whole range of temperature studied from M-T curve of the $\mathrm{Ni}_{0} \mathrm{NCs}$ sample (Fig. 16a) suggests that the sample is purely diamagnetic which supports the result of M-H measurement. Moreover, the positive magnetization from M-T curve (Fig. 16b) in whole range of temperature which indicates presence of magnetic interactions in $\mathrm{Ni}_{4} \mathrm{NCs}$ samples. To validate the origin of magnetic ordering, the M-T curve of $\mathrm{Ni}_{4} \mathrm{NCs}$ is analyzed. So we have applied

the standard Curie law, $\frac{M}{H}=\frac{C}{T}$ where $\mathrm{C}$ being the Curie constant and $\mathrm{T}$ is temperature to the $\mathrm{M}-\mathrm{T}$ 
curve, which resulted a suitable fitting at whole range of observed temperature (Fig.16 b). This result supports that Ni doped ZnS nanocrystals samples exhibit defect induced paramagnetism.

\section{Conclusions}

The $\mathrm{Zn}_{1-\mathrm{x}} \mathrm{Ni}_{\mathrm{X}} \mathrm{S}$ nanocrystals are prepared prosperously by aquatic synthesis route. The Rietveld refinement data obtained from XRD pattern shows decrease of inter-planner spacing due to Ni doping in $\mathrm{ZnS}$ lattice, though no major structural change have been observed, which is also correlated with Raman spectroscopy investigations. Scanning electron microscopy shows the spherulite morphology of the samples. A defect induced cyan emission peak observed in the photoluminescence spectra of all $\mathrm{Ni}$ doped ZnS. XANES and EXAFS measurements at $\mathrm{Ni} \mathrm{K}$-edge confirms that $\mathrm{Ni}^{2+}$ ions are incorporated into $\mathrm{ZnS}$ lattice and also indicates formation of $\mathrm{NiSO}_{4}$ nanoclusters. The ' $3 d$ ' orbital state with $1 s \rightarrow 3 d$ transition is responsible for single pre-edge feature on $\mathrm{Zn}_{1-\mathrm{X}} \mathrm{Ni}_{\mathrm{X}} \mathrm{S}$ nanocrystals and it has been evidenced that amplitude of such pre-edge is independent of $\mathrm{Ni}$ dopant on $\mathrm{Zn}_{1-\mathrm{x}} \mathrm{Ni}_{\mathrm{x}} \mathrm{S}$ nanocrystals. The undoped samples are diamagnetic while the doped samples are found to be paramagnetic due to presence or defects or $\mathrm{NiSO}_{4}$ nanoclusters.

\section{Appendix A. Supplementary Materials}

Please see supplementary materials for HRTEM images, EDS images, Tauc plots, Inverse susceptibility vs. temperature plot, Refined structural profile parameters of prepared nanocrystals.

\section{Compliance with ethical standards}

\section{Conflicts of interest}

It has been declared by all authors that there are no conflicts of interests regarding the publication of this article.

\section{Acknowledgements}

S.Ghorai thankful to Council of Scientific and Industrial Research (CSIR), Govt. of India for financial support. Dr. Anup K. Ghosh is thankful to DST-FIST program for financial support. We are thankful to Dr. V. Sathe for Raman measurements UGC-DAE, Indore. We are thankful to Prof. D.S. Pandey, Dept. of Chemistry, Institute of Science, BHU for photoluminescence measurements. XRD and HRTEM measurements are carried out at "Central Instrument Facility Centre" (CFIC), IITBHU. 


\section{References}

[1] R.S. Kumar, V. Veeravazhuthi, N. Muthukumarasamy, M. Thambidurai, D. Vishnu Shankar, Effect of nickel doping on structural and optical properties of $\mathrm{ZnS}$ nanoparticles, Superlattice Microstruct. 86 (2015) 552 -558

[2] M. Dimitrievska, H. Xie, A. J. Jackson, X. Fontane, M. Espindola-Rodrlguez, E. Saucedo, A. Perez-Rodriguez, A. Walsh, V. Izquierdo-Roc, Resonant Raman scattering of $\mathrm{ZnS}_{\mathrm{x}} \mathrm{Se}_{1-\mathrm{x}}$ solid solutions: the role of S and Se electronic states, Phys. Chem. Chem. Phys. 18 ( 2016) 7632-7640

[3] V. Ramasamy, K. Praba, G. Murugadoss, Study of optical and thermal properties in nickel doped ZnS nanoparticles using surfactants, Superlattice Microstruct. 51 (2012) 699 714

[4] R. Sahrei, S. Darafrin, Preparation of nanocrystalline Ni doped ZnS thin films by ammoniafree chemical bath deposition method and optical properties, J. Lumin. 182 (2014) 170-175

[5] J. Yang, T. Wang, J. Cao, L. Fan, X. Zhang, D. Han, B. Wang, Q. Liu, H. Niu, K. Lin, Facile and shape-controlled growth of the wurtzite $\mathrm{ZnS}: \mathrm{Ni}^{2+}$ nanoparticles and nanowires, Superlattice Microstruct. 71 (2014) 217 -224

[6] N. Priyadharsini, M. Elango, S. Vairam, M. Thamilselvan, Effect of nickel substitution on structural, optical, magnetic properties and photocatalytic activity of $\mathrm{ZnS}$ nanoparticles, Mat. Sci. Semicon. Proc. 49 (2016) 68-75

[7] S. Kumar, C.L. Chen, C.L. Dong, Y.K. Ho, J.F. Lee, T.S. Chan, R. Thangavel, T.K. Chen, B.H. Mok, S.M. Rao, M.K. Wu, Room temperature ferromagnetism in Ni doped ZnS nanoparticles, J. Alloy. Compd. 554 (2013) 357-362

[8] M. Molaei, F. Karimimaskon, A. Lotfiani, M. Samadpour, H. Liu, Synthesis of ZnS:Ni nanocrystals (NCs) using a rapid microwave activated method and investigation of the structural and optical properties, J. Lumin. 143 (2013) 649 - 652

[9] R. Long, N.J. English, Magnetic properties of first-row element-doped $\mathrm{ZnS}$ semiconductors: A density functional theory investigation, Phys. Rev. B 80 (2009) $115212-115216$

[10] H. Chen, D. Shi, J. Qi, Comparative studies on the magnetic properties of ZnS nanowires doped with transition metal atoms, J. Appl. Phys. 109 (2011) 084338-084339

[11] H.Q. Xie, L. J. Tang, J. L. Tang, P. Peng, Magnetic properties of Ni doped ZnS: Firstprinciples study, J. Magn. Magn. Mater. 377 (2015) 239-242

[12] D.Saika, J. P. Borah, Investigations of doping induced structural, optical and magnetic properties of $\mathrm{Ni}$ doped $\mathrm{ZnS}$ diluted magnetic semiconductors, J. Mater. Sci: Mater. Electron. 28 (2017) 8029-8037 
[13] M.A. Aktar, M.A. Malik,S. Riaz, S. Naseem, Room temperature ferromagnetism and half metallicity in nickel doped ZnS: Experimental and DFT studies, Mater. Chem. Phys. 160 (2015) 440-445

[14] M. Schulz, G.G. Wepfer, Paramagnetic resonance of nickel doped ZnS and CdS crystals, Solid. State. Commun. 10 (1972) 405-408

[15] W.F.P. Pong, R.A. Mayanovic, K.T. Wu, P.K. Tseng, B.A. Bunker, A. Hiraya, M. Watanabe, Influence of transition metal type and content on local order properties of $\mathrm{Zn}_{1-}$ ${ }_{x} \mathrm{M}_{\mathrm{x}} \mathrm{S}(\mathrm{M}=\mathrm{Mn}, \mathrm{Fe}, \mathrm{Co})$ alloys studied using XANES spectroscopy, Phys. Rev. B 50(11) (1994) 7371-7377

[16] K.L. Jablonska, R.J. Iwanowski, Z. Gołacki, A. Traverse, S. Pizzini, A. Fontaine, I. Winter, J. Hormes, Local electronic structure of $\mathrm{ZnS}$ and $\mathrm{ZnSe}$ doped by $\mathrm{Mn}, \mathrm{Fe}$, Co and $\mathrm{Ni}$ from X-ray-absorption near edge structure studies, Phys. Rev. B 53(3) (1996) 1119-1128

[17] A. K. Rana, Y. Kumar, P. Rajput, S. N. Jha, D. Bhattacharyya and P. M. Shirage, Search for Origin of Room Temperature Ferromagnetism Properties in Ni doped ZnO Nanostructure, ACS Appl. Mater. Interfaces 9(8) (2017) 7691-7700

[18] A. A. Othman, M. A. Osman, Manar A. Ali, W. S. Mohamed, E. M. M. Ibrahim, Sonochemically synthesized Ni-doped $\mathrm{ZnS}$ nanoparticles: structural, optical and photocatalytic properties; J. Mater. Sci: Mater. Electron. 31(2020) 1752-1767

[19] A.K. Poswal, A. Agrawal, A.K. Yadav, C. Nayak, S. Basu, S.R. Kane, C.K. Garg, D. Bhattacharyya, S.N.Jha, N.K. Sahoo, Commissioning and first results of scanning type EXAFS beam line (BL-09) at INDUS-2 synchrotron source, A.I.P. Conf. Proc. 1591 (2014) 649-651

[20] K.M. Hanif, R.W. Meulenberg, G.F. Strouse, Magnetic Ordering in Doped $\mathrm{Cd}_{1-\mathrm{x}} \mathrm{Co}_{\mathrm{x}} \mathrm{Se}$ Diluted Magnetic Quantum Dots, J. Am. Chem. Soc. 124 (2002) 11495-11502

[21] S. Basu, C. Nayak, A.K. Yadav, A. Agrawal, A.K. Poswal, D. Bhattacharyya, S.N. Jha, N.K. Sahoo, A comprehensive facility for EXAFS measurements at the INDUS-2 synchrotron source at RRCAT, Indore, India, J. Phys.: Conf. Ser. 493 (2014) 012032

[22] https://icsd.fiz-karlsruhe.de

[23] M. Wu, Z. Wei, W. Zhao, X. Wang, J. Jiang, Optical and magnetic properties of Ni doped $\mathrm{ZnS}$ diluted magnetic semiconductors synthesized by hydrothermal method, J. Nanomater. 2017 (2017) 1603450

[24] Z.F. Liu, F.K. Shan, J.Y. Sohn, S.C. Kim, G.Y. Kim, Y.X. Li, Photo luminescence of ZnO: Ga thin flims fabricated by pulsed laser deposition technique. J. Electro ceramics 13(1-3), 183-187(2004)

[25] M. Cardona, Light Scattering in Solids V, vol. 66, Springer, Berlin, Germany,1989, pp. 138140 
[26] W.G. Nilsen, Raman spectrum of cubic ZnS, Magnetic Ordering in Doped $\mathrm{Cd}_{1-\mathrm{x}} \mathrm{Co}_{\mathrm{x}} \mathrm{Se}$ Diluted Magnetic Quantum Dots, Phys. Rev. 182 (1969) 838

[27] J.Tauc, Amorphous and Liquid Semiconductors, Plenum, New York, USA, 1974

[28] S. Sapra, D. D. Sarma, Electronic Structure and Spectroscopy of Semiconductor Nanocrystals, in The Chemistry of Nanomaterials, C.N. Rao, A. Muller, A.K. Cheetham (Eds.), Wiley VCH, Germany, 2, Ch 11, 2004, 375-404

[29] L. Liu, L. Yang, Y. Pu, D. Xiao, J. Zhu, Optical properties of water-soluble $\mathrm{Co}^{2+}$ : ZnS semiconductor nanocrystals synthesized by a hydrothermal process. Mater. Lett. 66(1), 121-1 $24(2012)$

[30] E. Burstein, Anomalous Optical Absorption Limit in InSb, Phys. Rev. 93 (1954) 632-633

[31] W.S. Ni, Y.J. Lin, C.J. Liu, Y.W. Yang, L. Horng, Luminescence, structural and ferromagnetic properties of $\mathrm{Zn}_{1-\mathrm{x}} \mathrm{Mn}_{\mathrm{x}} \mathrm{S}_{\mathrm{y}}$ films for different manganese contents, J. Alloy, Compd 556 (2013) 178-181

[32] A.K. Shahi, B.K. Pandey, R.K. Swarnkar, R. Gopal, Surfactant assisted surface studies of zinc sulfide nanoparticles, Appl. Surf. Sci. 257 (2011) 9846-9851

[33] B. Poornaprakash, D. A. Reddy, G. Murali, R.P. Vijayalakshmi, B.K. Reddy, Defect induced paramagnetism in lightly doped ZnS:Fe nanoparticles, Physica E Low Dimens. Syst. Nanostruct. 73 (2015) 63-68

[34] U. Thibblint, S.R. Micnas, K.A. Chaot, Theory of bound magnetic polarons in diluted magnetic semiconductors, J. Phys. Condens. Matter 1 (1989) 941-956

\section{Table Captions}

Table 1. EDS analysis of $\mathrm{Zn}_{1-\mathrm{X}} \mathrm{Ni}_{\mathrm{X}} \mathrm{S}(0 \leq x \leq 0.04)$ nanocrystals samples

Table 2. Raman peaks of $\mathrm{Zn}_{1-\mathrm{X}} \mathrm{Ni}_{\mathrm{X}} \mathrm{S}(0 \leq x \leq 0.04)$ nanocrystals and their symmetry assignments

Table 3. The best fitted structural parameters obtained from EXAFS data at $\mathrm{Zn} \mathrm{K-}$ edge

Table 4. The best fitted structural parameters obtained from EXAFS data at Ni Kedge 


\section{Figure Captions}

Fig. 1. X-ray diffraction data of $\mathrm{Zn}_{1-\mathrm{X}} \mathrm{Ni}_{\mathrm{X}} \mathrm{S}(0 \leq x \leq 0.04)$ nanocrystals with Rietveld refinement

Fig. 2. Change in (a) lattice parameter and (b) (111) inter-planar spacing of $\mathrm{Zn}_{1-\mathrm{X}} \mathrm{Ni}_{\mathrm{X}} \mathrm{S}$ ( $0 \leq x \leq 0.04$ ) nanocrystals obtained from Rietveld refinement

Fig. 3. The SEM images of (a) $\mathrm{Ni}_{0}$, (b) $\mathrm{Ni}_{1}$, (c) $\mathrm{Ni}_{2}$ and (d) $\mathrm{Ni}_{4}$ nanocrystals (magnification fixed at $60 \mathrm{KX}$ )

Fig. 4. (a), (b) and (c) demonstrated low magnification TEM, HRTEM and SAED images of $\mathrm{Ni}_{0}$ nanocrystals respectively; (d), (e) and (f) showed low magnification TEM, HRTEM and SAED images of $\mathrm{Ni}_{4}$ nanocrystals respectively

Fig. 5. Raman spectrum of the $\mathrm{Zn}_{1-\mathrm{X}} \mathrm{Ni}_{\mathrm{X}} \mathrm{S}(0 \leq x \leq 0.04) \mathrm{NCs}$ observed at room temperature excited with wavelength $632.81 \mathrm{~nm}$

Fig. 6. The UV-visible absorption spectrum of $\mathrm{Zn}_{1-\mathrm{x}} \mathrm{Ni}_{\mathrm{X}} \mathrm{S}(0 \leq x \leq 0.04)$ nanocrystals and inset plot shows change of energy band gap of prepared samples

Fig. 7. The normalized XANES data of the $\mathrm{Zn}_{1-\mathrm{X}} \mathrm{Ni}_{\mathrm{X}} \mathrm{S}(0 \leq x \leq 0.04)$ nanocrystals observed at $\mathrm{Zn}$ K-edge

Fig.8. The $k^{2}$ weighted $\chi(k)$ spectra obtained at $\mathrm{Zn}$ K-edge of the $\mathrm{Zn}_{1-\mathrm{X}} \mathrm{Ni}_{\mathrm{X}} \mathrm{S}(0 \leq x \leq 0.04)$ nanocrystals

Fig. 9. The best fitted experimental $\chi(R)$ vs. $R$ data with theoretically created plot (showed in solid line) at $\mathrm{Zn} \mathrm{K}$-edge of (a) $\mathrm{Ni}_{0}$, (b) $\mathrm{Ni}_{0.5}$, (c) $\mathrm{Ni}_{1}$, (d) $\mathrm{Ni}_{2}$ and (e) $\mathrm{Ni}_{4}$ nanocrystals

Fig. 10. The normalized XANES data observed at Ni K-edge of the $\mathrm{Zn}_{1-\mathrm{x}} \mathrm{Ni}_{\mathrm{x}} \mathrm{S}$ nanocrystals

Fig. 11. The pre-edge characteristic of the nickel doped $\mathrm{ZnS}$ NCs with reference to NiS and $\mathrm{NiSO}_{4}$ samples at $\mathrm{Ni} \mathrm{K}$-edge

Fig. 12. The $k^{2}$ weighted $\chi(k)$ spectra obtained at $\mathrm{Ni}$ K-edge of the $\mathrm{Zn}_{1-\mathrm{X}} \mathrm{Ni}_{\mathrm{X}} \mathrm{S}$ nanocrystals

Fig. 13. The best fitted experimental $\chi(R)$ vs. $R$ data with theoretically created data (showed in solid line) at $\mathrm{Ni} \mathrm{K}$-edge of the $\mathrm{Zn}_{1-\mathrm{X}} \mathrm{Ni}_{\mathrm{X}} \mathrm{S}$ nanocrystals

Fig. 14. The photoluminescence spectrum of $\mathrm{Zn}_{1-\mathrm{x}} \mathrm{Ni}_{\mathrm{X}} \mathrm{S}(0 \leq x \leq 0.04)$ nanocrystals observed by exciting at $320 \mathrm{~nm}$

Fig. 15. Magnetization $v s$. applied field measured in the range of $\pm 20000 \mathrm{Oe}$ at $300 \mathrm{~K}$ of $\mathrm{Ni}_{1}, \mathrm{Ni}_{2}$, nanocrystals samples and the inset is the magnetization of $\mathrm{Ni}_{0}$ nanocrystals observed in the range of \pm 70000 Oe at $300 \mathrm{~K}$

Fig. 16. Magnetization vs. temperature plot of (a) $\mathrm{Ni}_{0}$ nanocrystals and (b) $\mathrm{Ni}_{4}$ nanocrystals (with fitting) at fixed field of $1000 \mathrm{Oe}$ 


\section{Tables}

Table 1. EDS analysis of $\mathrm{Zn}_{1-\mathrm{X}} \mathrm{Ni}_{\mathrm{X}} \mathrm{S}(0 \leq x \leq 0.04)$ nanocrystals samples

\begin{tabular}{|c|c|c|}
\hline Sample & Zinc Sulfide & Nickel \\
\hline $\mathrm{Ni}_{0}$ & 100 & 0 \\
$\mathrm{Ni}_{1}$ & $99.03( \pm 0.01)$ & $0.97( \pm 0.01)$ \\
$\mathrm{Ni}_{2}$ & $98.08( \pm 0.03)$ & $1.92( \pm 0.03)$ \\
$\mathrm{Ni}_{4}$ & $96.07( \pm 0.02)$ & $3.93( \pm 0.02)$ \\
\hline
\end{tabular}

Table 2. Raman peaks of $\mathrm{Zn}_{1-\mathrm{X}} \mathrm{Ni}_{\mathrm{X}} \mathrm{S}(0 \leq x \leq 0.04)$ nanocrystals and their symmetry assignments

\section{Vibration frequency $\left(\mathrm{cm}^{-1}\right)$}

\begin{tabular}{|l|l|l|l|l|l|}
\hline $\mathrm{Ni}_{0}$ & $\mathrm{Ni}_{1}$ & $\mathrm{Ni}_{2}$ & $\mathrm{Ni}_{4}$ & Assignments & Process \\
\hline 263 & 263 & 266 & 267 & $\begin{array}{c}\text { Transverse } \\
\text { optical mode }\end{array}$ & \\
\hline 347 & 348 & 349 & 349 & $\begin{array}{l}\text { Longitudinal } \\
\text { optical mode }\end{array}$ & $1^{\text {st }}$ Order \\
\hline
\end{tabular}


Table 3. The best fitted structural parameters obtained from EXAFS data at $\mathrm{Zn} \mathrm{K}$ edge

\begin{tabular}{|c|c|c|c|}
\hline \multirow{2}{*}{ Sample } & \multicolumn{3}{|c|}{$\begin{array}{c}\text { Scattering paths } \\
\mathrm{Zn}-\mathrm{S} \times 4\end{array}$} \\
\cline { 2 - 4 } & $R(\AA)$ & $\sigma^{2}\left(\AA^{2}\right)$ & $R_{\text {factor }}$ \\
\hline $\mathbf{N i}_{\mathbf{0}}$ & $2.26 \pm 0.01$ & $0.008 \pm 0.005$ & 0.008 \\
\hline $\mathbf{N i} \mathbf{0 . 5}$ & $2.26 \pm 0.01$ & $0.005 \pm 0.002$ & 0.006 \\
\hline $\mathbf{N i}_{\mathbf{1}}$ & $2.28 \pm 0.01$ & $0.006 \pm 0.002$ & 0.006 \\
\hline $\mathbf{N i}_{\mathbf{2}}$ & $2.28 \pm 0.01$ & $0.002 \pm 0.002$ & 0.004 \\
\hline $\mathbf{N i}_{4}$ & $2.28 \pm 0.01$ & $0.002 \pm 0.002$ & 0.005 \\
\hline
\end{tabular}

Table 4. The best fitted structural parameters obtained from EXAFS data at Ni Kedge

\begin{tabular}{|c|c|c|c|c|c|c|}
\hline $\begin{array}{c}\text { Scattering } \\
\text { paths }\end{array}$ & Parameters & $\mathbf{N i S O}_{4}$ & $\mathbf{N i}_{\mathbf{0}}$ & $\mathbf{N i}_{\mathbf{1}}$ & $\mathbf{N i}_{2}$ & $\mathbf{N i}_{\mathbf{4}}$ \\
\hline $\mathrm{Ni}-\mathrm{O} \times 6$ & $R(\AA)$ & $2.03 \pm 0.01$ & $2.04 \pm 0.01$ & $2.04 \pm 0.02$ & $2.03 \pm 0.02$ & $2.01 \pm 0.01$ \\
& $\sigma^{2}\left(\AA^{2}\right)$ & $0.006 \pm 0.001$ & $0.006 \pm 0.001$ & $0.006 \pm 0.001$ & $0.007 \pm 0.002$ & $0.005 \pm 0.002$ \\
\hline $\mathrm{Ni}-\mathrm{Ni} \times 2$ & $R(\AA)$ & $3.30 \pm 0.03$ & $3.09 \pm 0.02$ & $3.09 \pm 0.02$ & $3.04 \pm 0.05$ & $2.95 \pm 0.05$ \\
& $\sigma^{2}\left(\AA^{2}\right)$ & $0.029 \pm 0.009$ & $0.006 \pm 0.002$ & $0.010 \pm 0.006$ & $0.004 \pm 0.003$ & $0.012 \pm 0.010$ \\
\hline & $R_{\text {factor }}$ & 0.002 & 0.006 & 0.007 & 0.023 & 0.022 \\
\hline
\end{tabular}


Figures

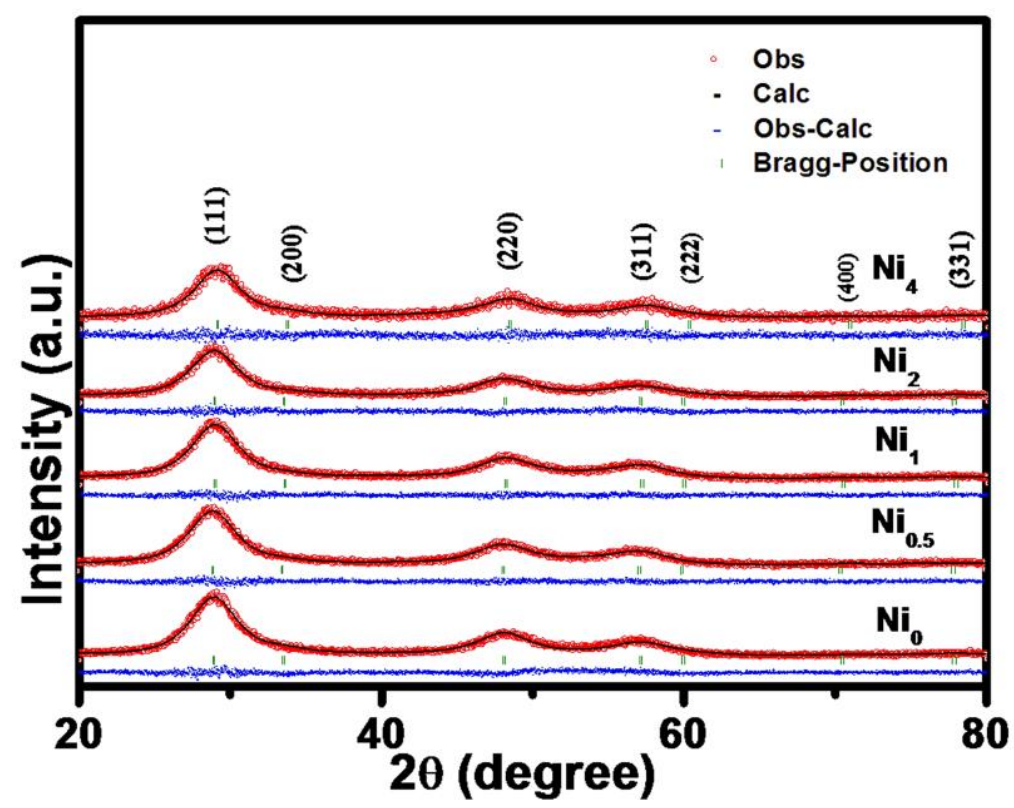

Fig. 1. X-ray diffraction data of $\mathrm{Zn}_{1-\mathrm{x}} \mathrm{Ni}_{\mathrm{X}} \mathrm{S}(0 \leq x \leq 0.04)$ nanocrystals with Rietveld refinement
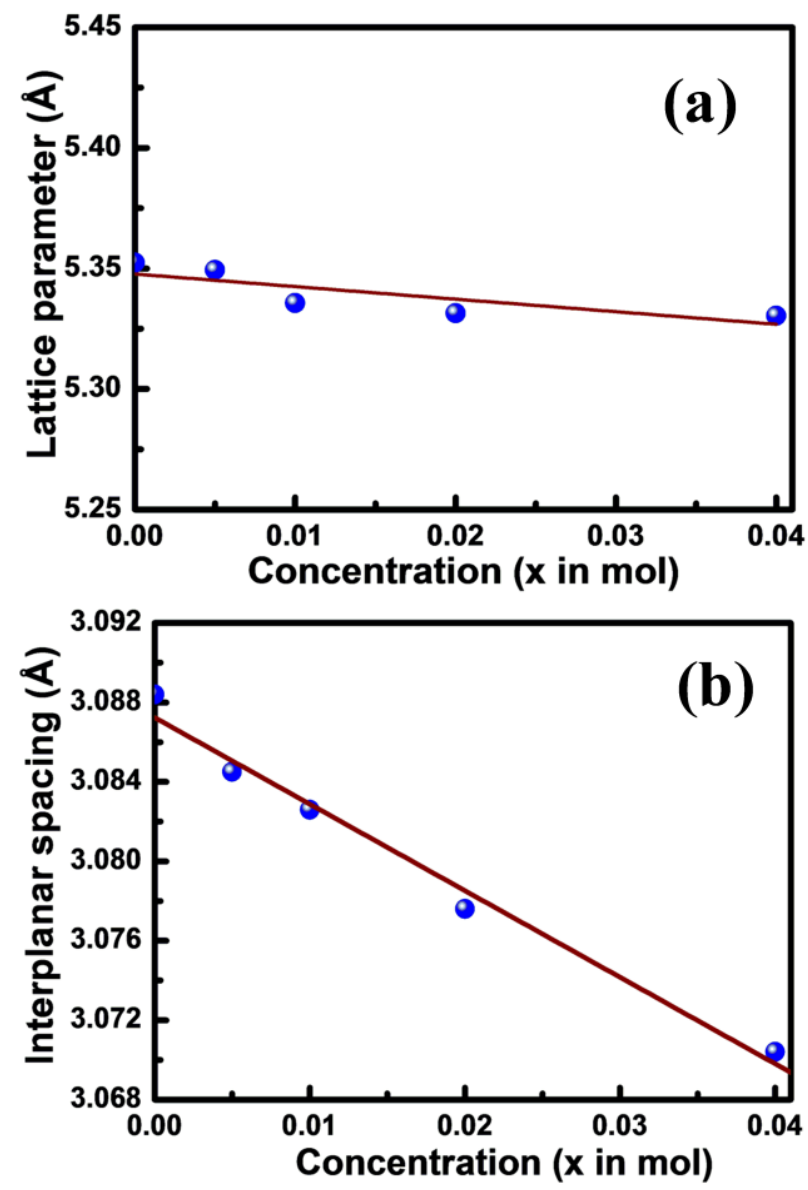

Fig. 2. Change in (a) lattice parameter and (b) (111) inter-planar spacing of $\mathrm{Zn}_{1-\mathrm{x}} \mathrm{Ni}_{\mathrm{X}} \mathrm{S}$ ( $0 \leq x \leq 0.04$ ) nanocrystals obtained from Rietveld refinement 


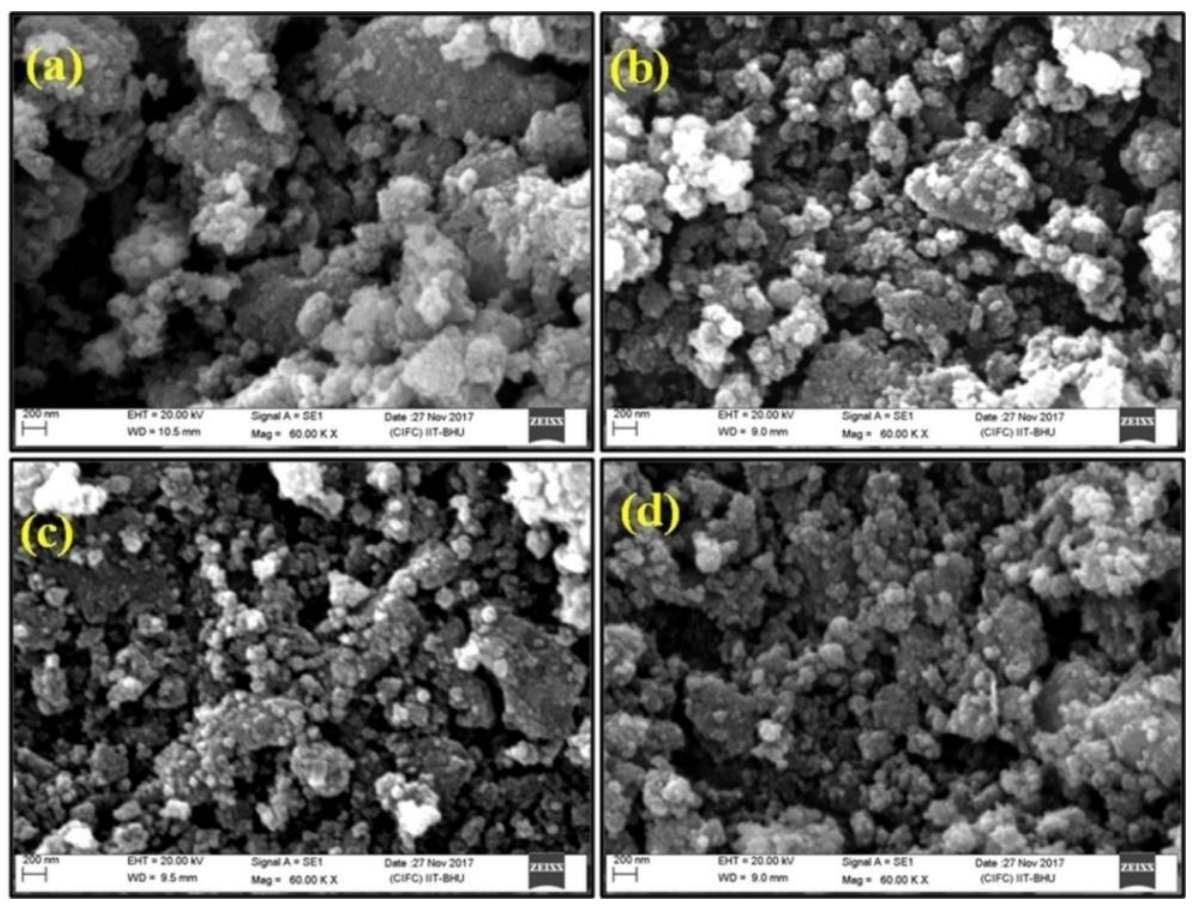

Fig. 3. The SEM images of (a) $\mathrm{Ni}_{0}$, (b) $\mathrm{Ni}_{1},(c) \mathrm{Ni}_{2}$ and (d) $\mathrm{Ni}_{4}$ nanocrystals (magnification fixed at $60 \mathrm{KX}$ ) 


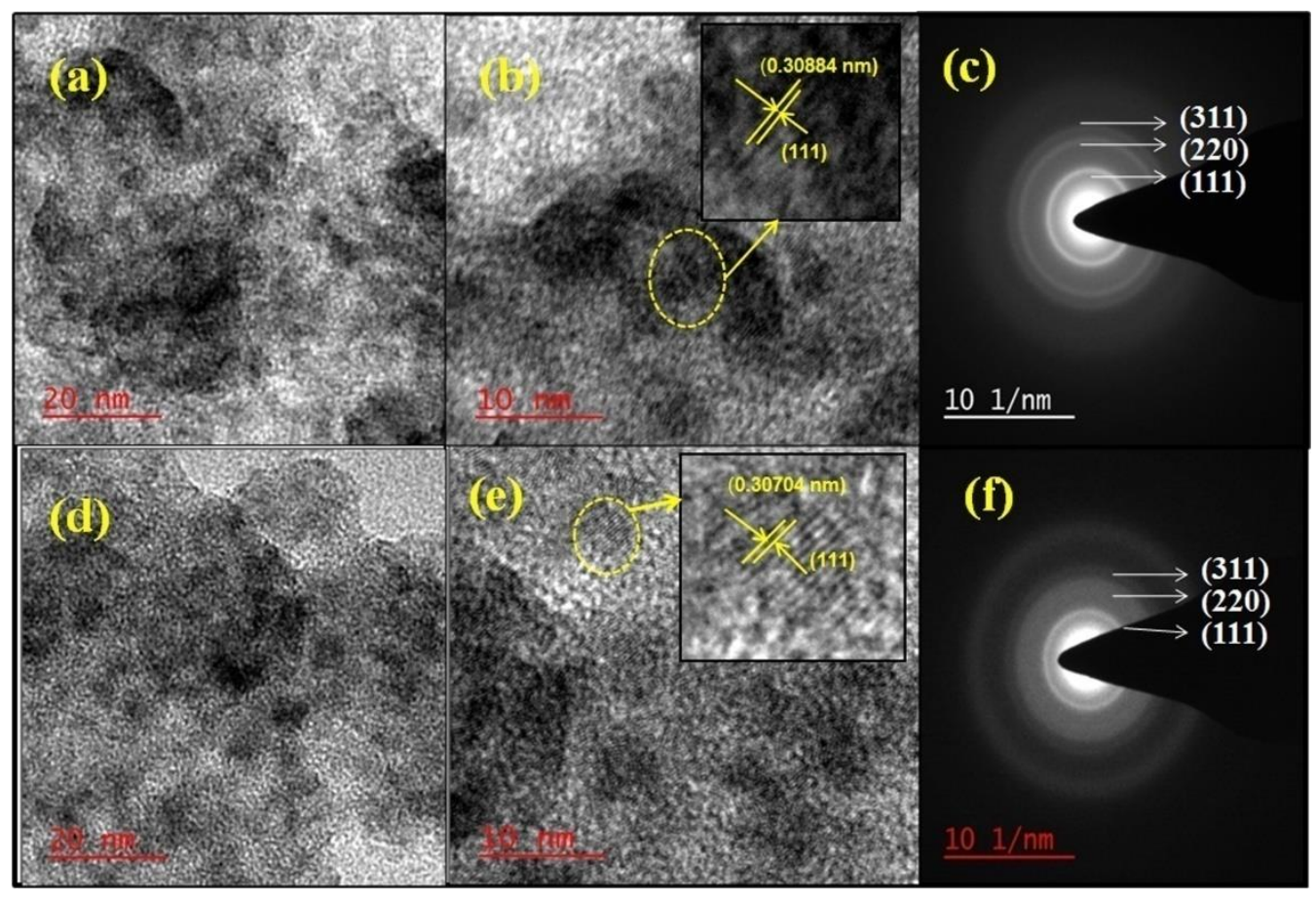

Fig. 4. (a), (b) and (c) demonstrated low magnification TEM, HRTEM and SAED images of $\mathrm{Ni}_{0}$ nanocrystals respectively; $(d),(e)$ and $(f)$ showed low magnification TEM, HRTEM and SAED images of $\mathrm{Ni}_{4}$ nanocrystals respectively 


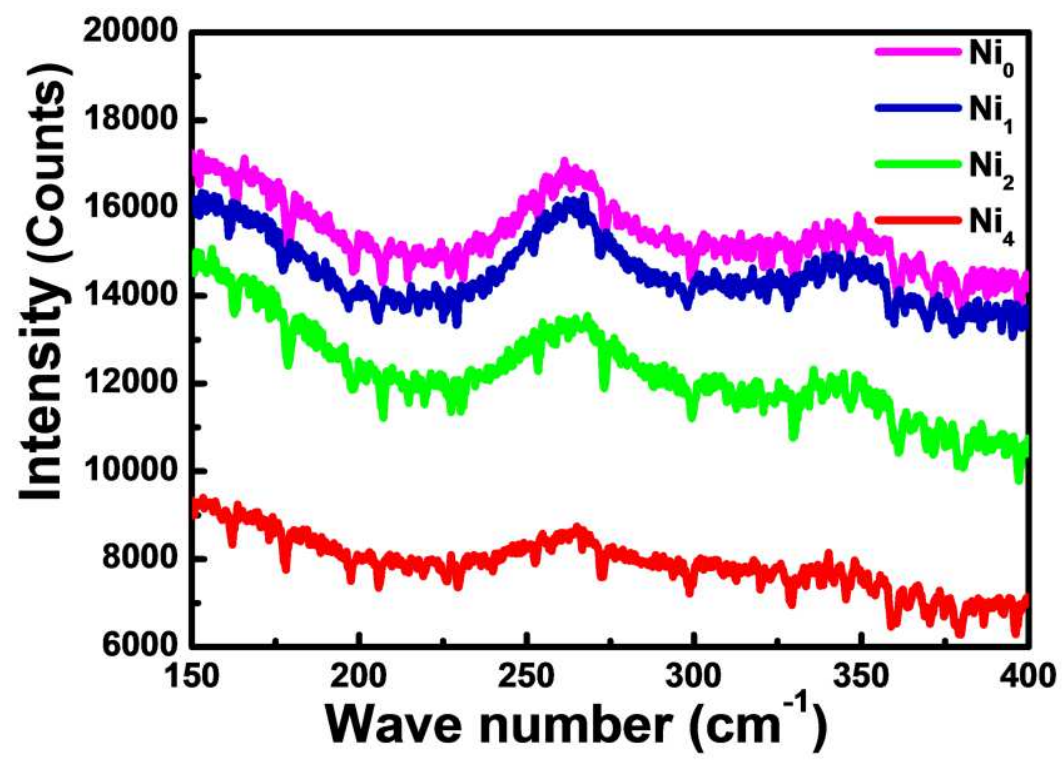

Fig. 5. Raman spectrum of the $\mathrm{Zn}_{1-\mathrm{x}} \mathrm{Ni}_{\mathrm{X}} \mathrm{S}(0 \leq x \leq 0.04)$ NCs observed at room temperature excited with wavelength $632.81 \mathrm{~nm}$ 


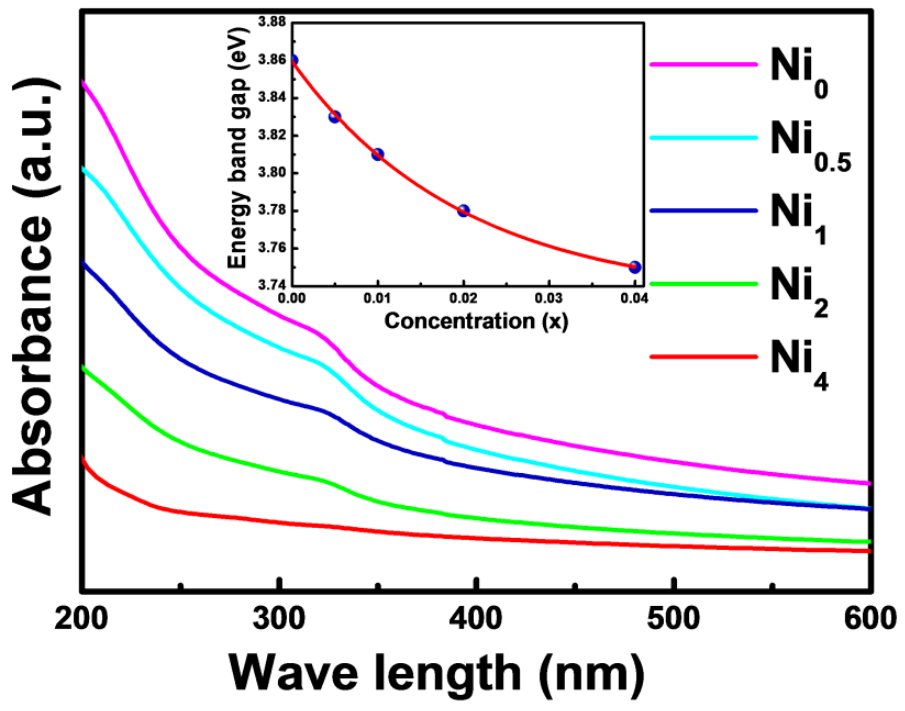

Fig. 6. The $U V$-visible absorption spectrum of $\mathrm{Zn}_{1-\mathrm{x}} \mathrm{Ni}_{\mathrm{X}} \mathrm{S}(0 \leq x \leq 0.04)$ nanocrystals and inset plot shows change of energy band gap of prepared samples 


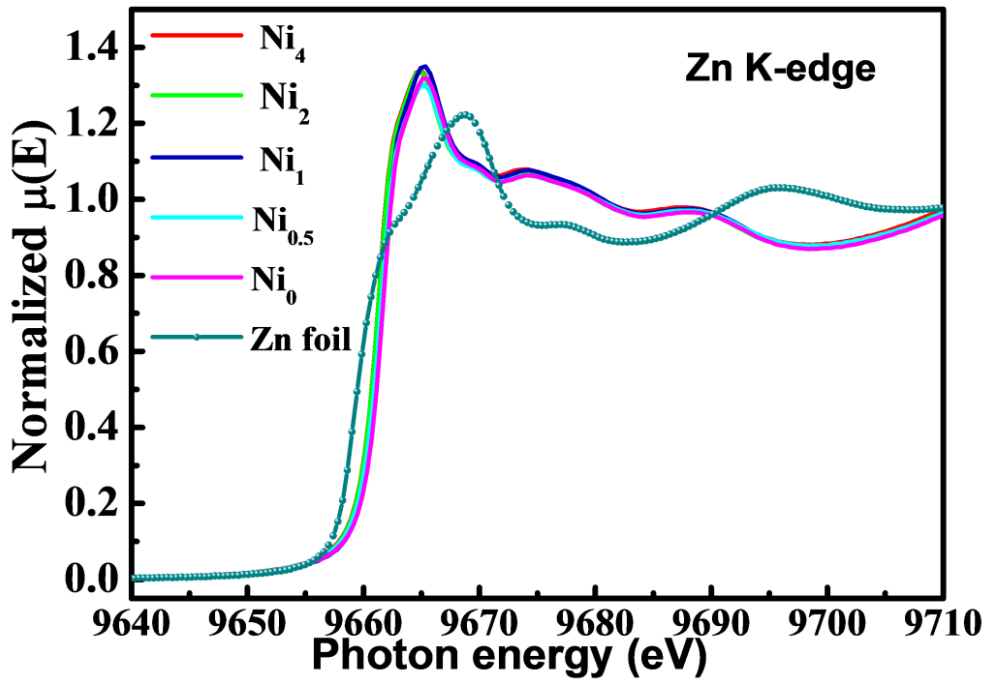

Fig. 7. The normalized XANES data of the $\mathrm{Zn}_{1-\mathrm{x}} \mathrm{Ni}_{\mathrm{X}} \mathrm{S}(0 \leq x \leq 0.04)$ nanocrystals observed at $\mathrm{Zn}$ K-edge 


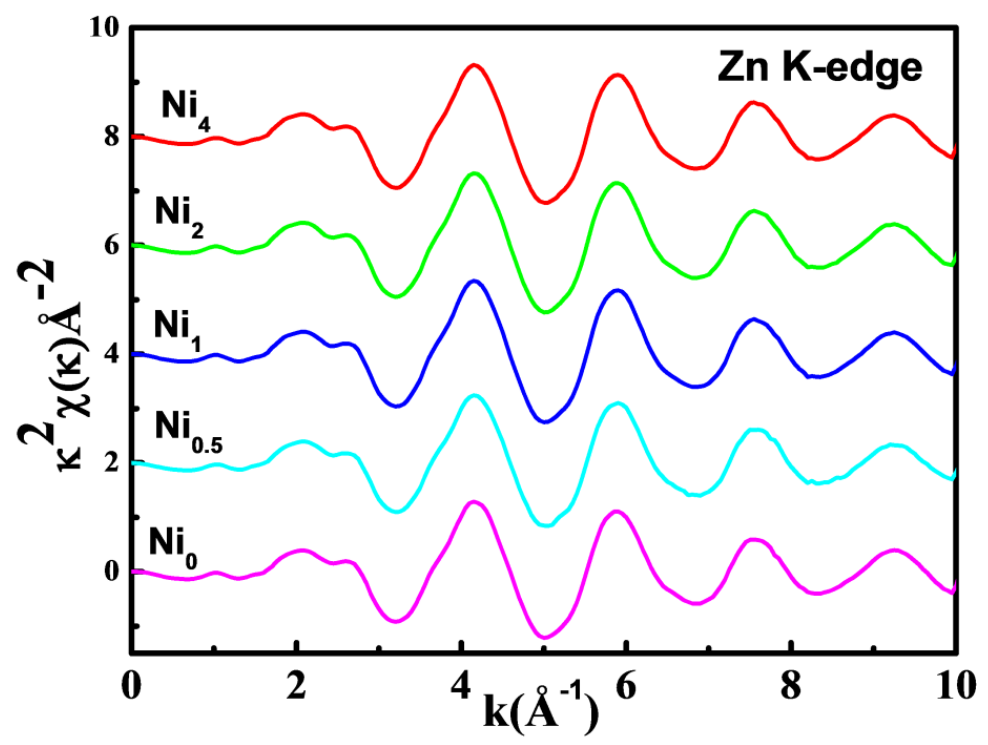

Fig. 8. The $k^{2}$ weighted $\chi(k)$ spectra obtained at $\mathrm{Zn}$ K-edge of the $\mathrm{Zn}_{1-\mathrm{X}} \mathrm{Ni}_{\mathrm{X}} \mathrm{S}(0 \leq x \leq 0.04)$ nanocrystals 

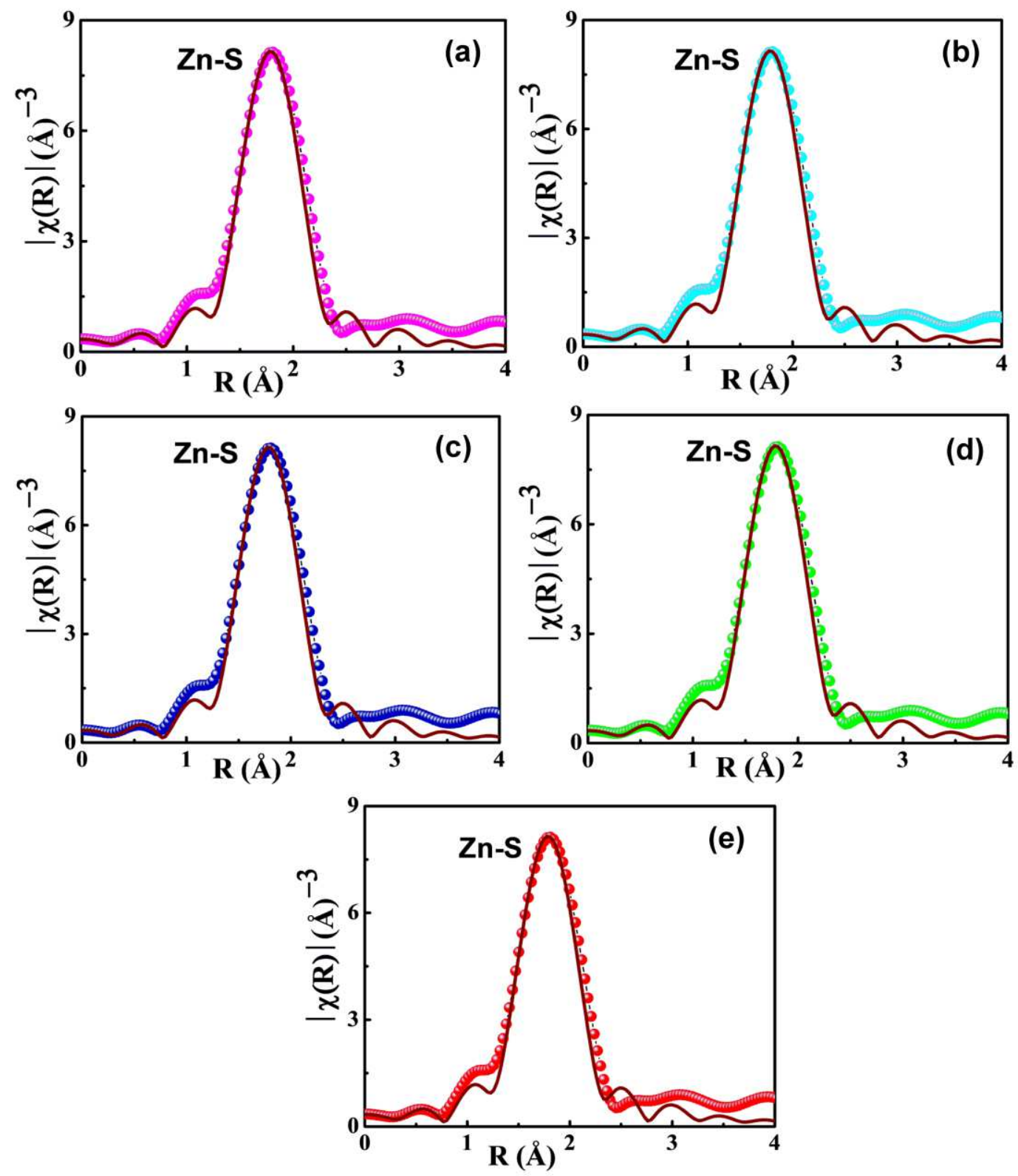

Fig. 9. The best fitted experimental $\chi(R)$ vs. $R$ data with theoretically created plot (showed in solid line) at $\mathrm{Zn} \mathrm{K}$-edge of (a) $\mathrm{Ni}_{0},(b) \mathrm{Ni}_{0.5},(c) \mathrm{Ni}_{1},(d) \mathrm{Ni}_{2}$ and (e) $\mathrm{Ni}_{4}$ nanocrystals 


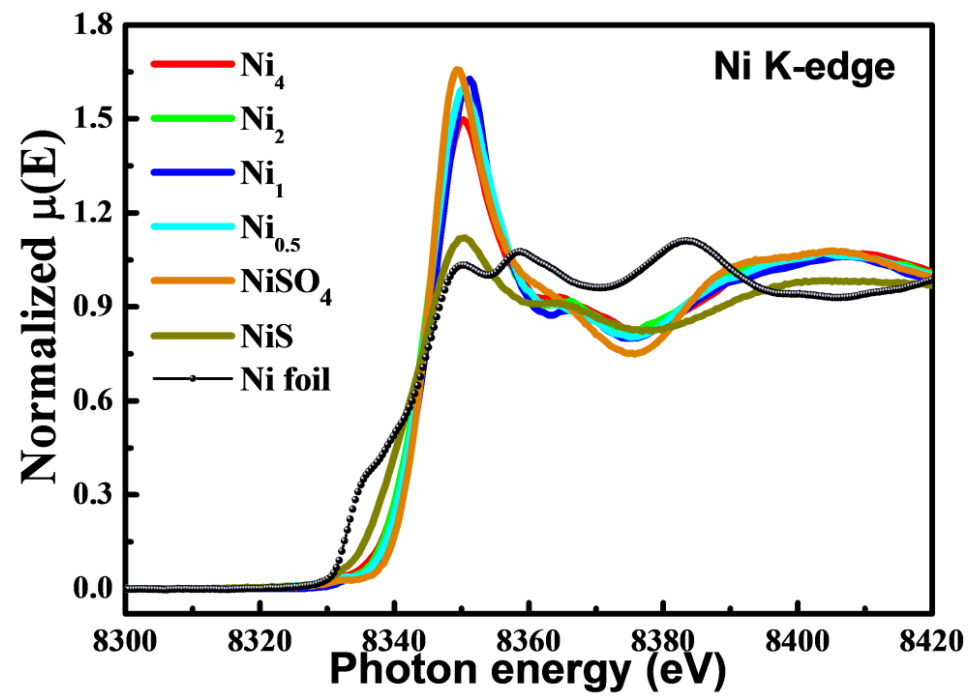

Fig. 10. The normalized XANES data observed at $\mathrm{Ni}$ K-edge of the $\mathrm{Zn}_{1-\mathrm{X}} \mathrm{Ni}_{\mathrm{X}} \mathrm{S}$ nanocrystals 


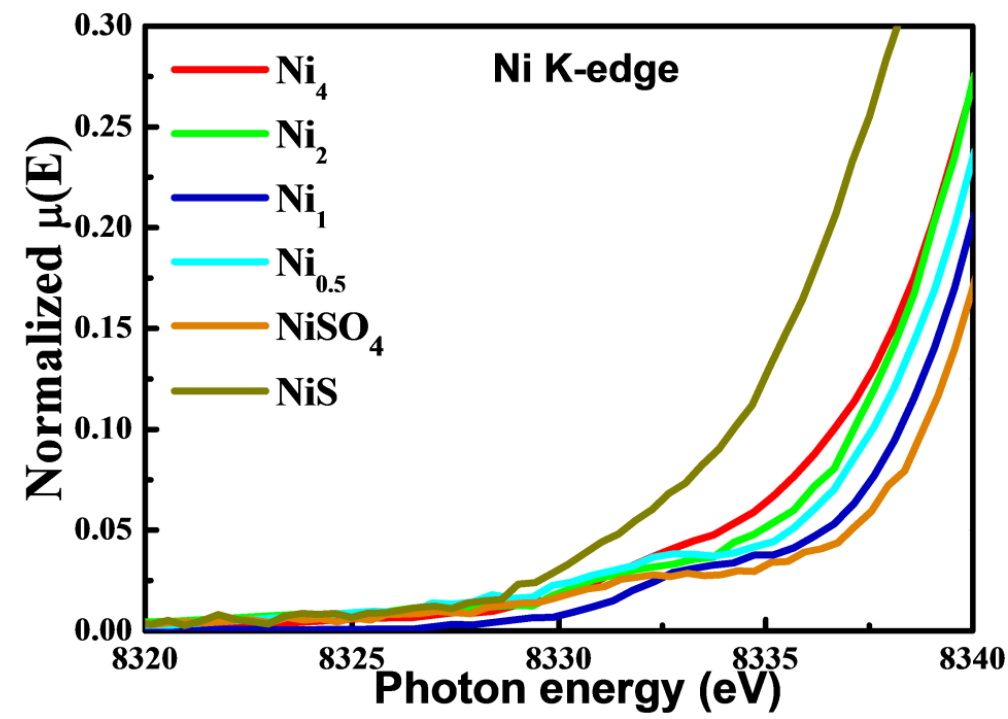

Fig. 11. The pre-edge characteristic of the nickel doped $\mathrm{ZnS} N C s$ with reference to NiS and $\mathrm{NiSO}_{4}$ samples at $\mathrm{Ni} \mathrm{K}$-edge 


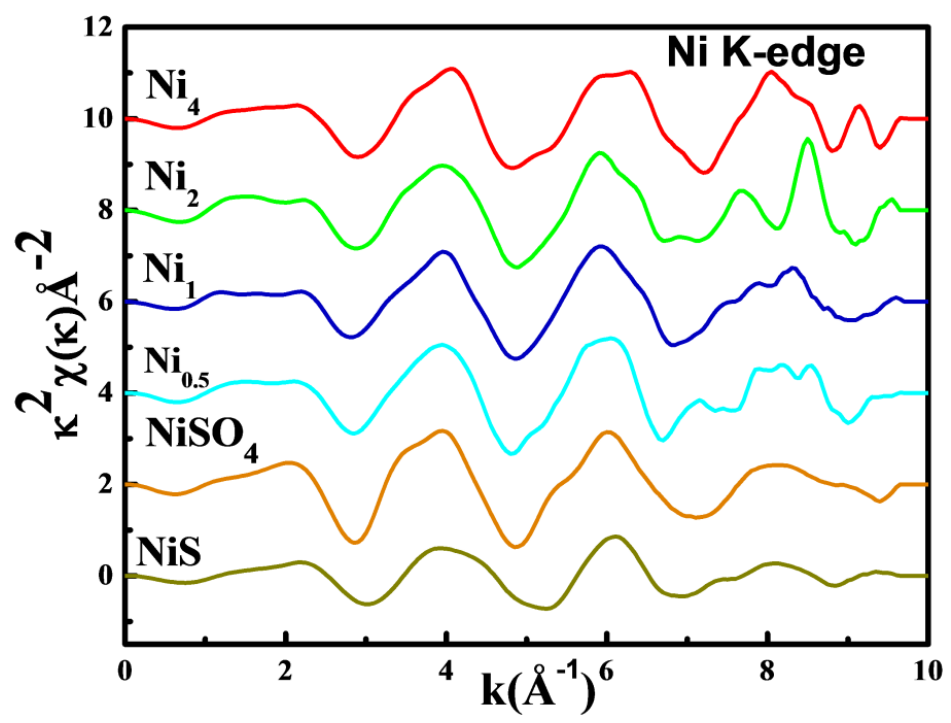

Fig. 12. The $k^{2}$ weighted $\chi(k)$ spectra obtained at Ni K-edge of the $\mathrm{Zn}_{1-\mathrm{X}} \mathrm{Ni}_{\mathrm{X}} \mathrm{S}$ nanocrystals 


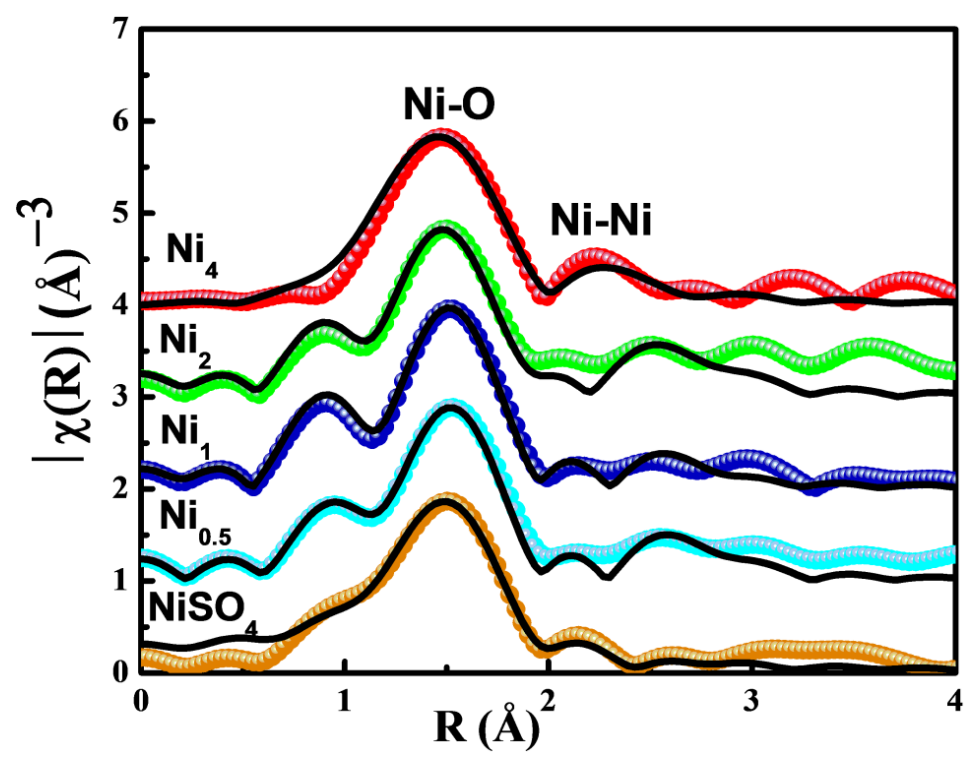

Fig. 13. The best fitted experimental $\chi(R)$ vs. $R$ data with theoretically created data (showed in solid line) at $\mathrm{Ni}$ K-edge of the $\mathrm{Zn}_{1-\mathrm{x}} \mathrm{Ni}_{\mathrm{X}} \mathrm{S}$ nanocrystals 


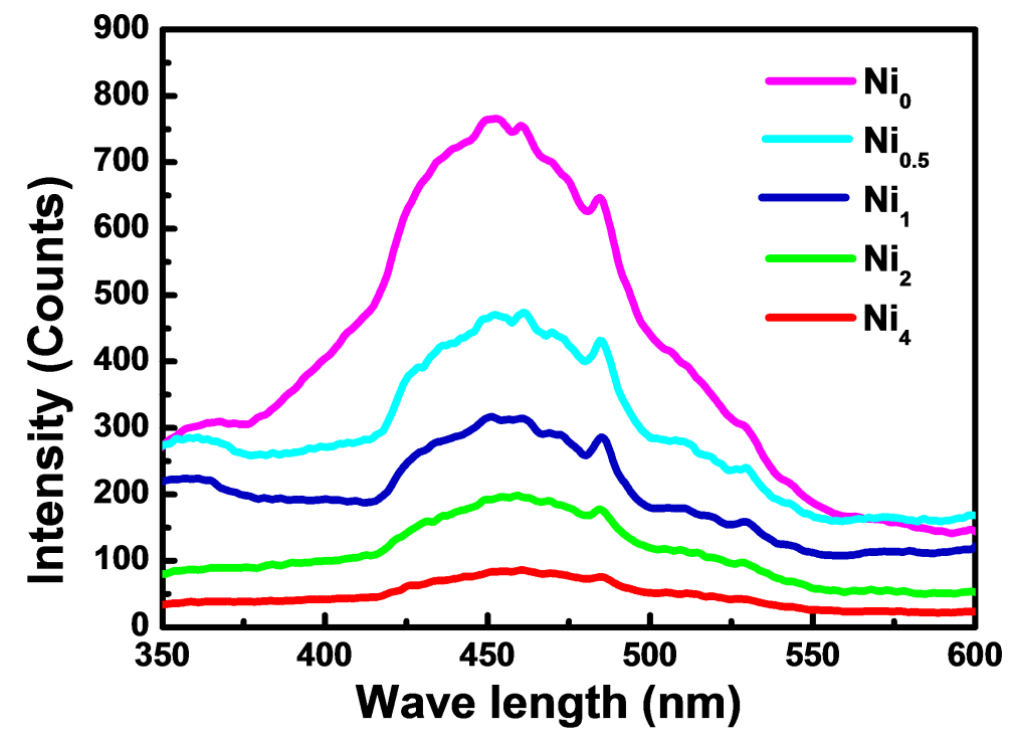

Fig. 14. The photoluminescence spectrum of $\mathrm{Zn}_{1-\mathrm{x}} \mathrm{Ni}_{\mathrm{X}} \mathrm{S}(0 \leq x \leq 0.04)$ nanocrystals observed by exciting at $320 \mathrm{~nm}$ 


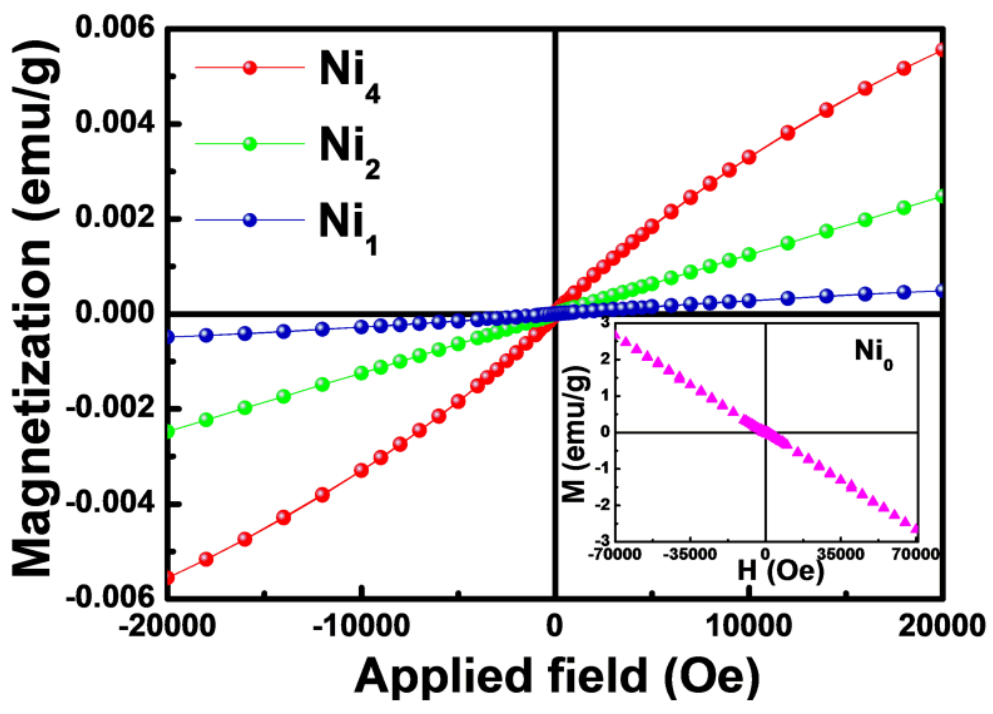

Fig. 15. Magnetization vs. applied field measured in the range of \pm 20000 Oe at $300 \mathrm{~K}$ of $\mathrm{Ni}_{1}, \mathrm{Ni}_{2}, \mathrm{Ni}_{4}$ nanocrystals samples and the inset is the magnetization of Nio nanocrystals observed in the range of \pm 70000 Oe at $300 \mathrm{~K}$ 

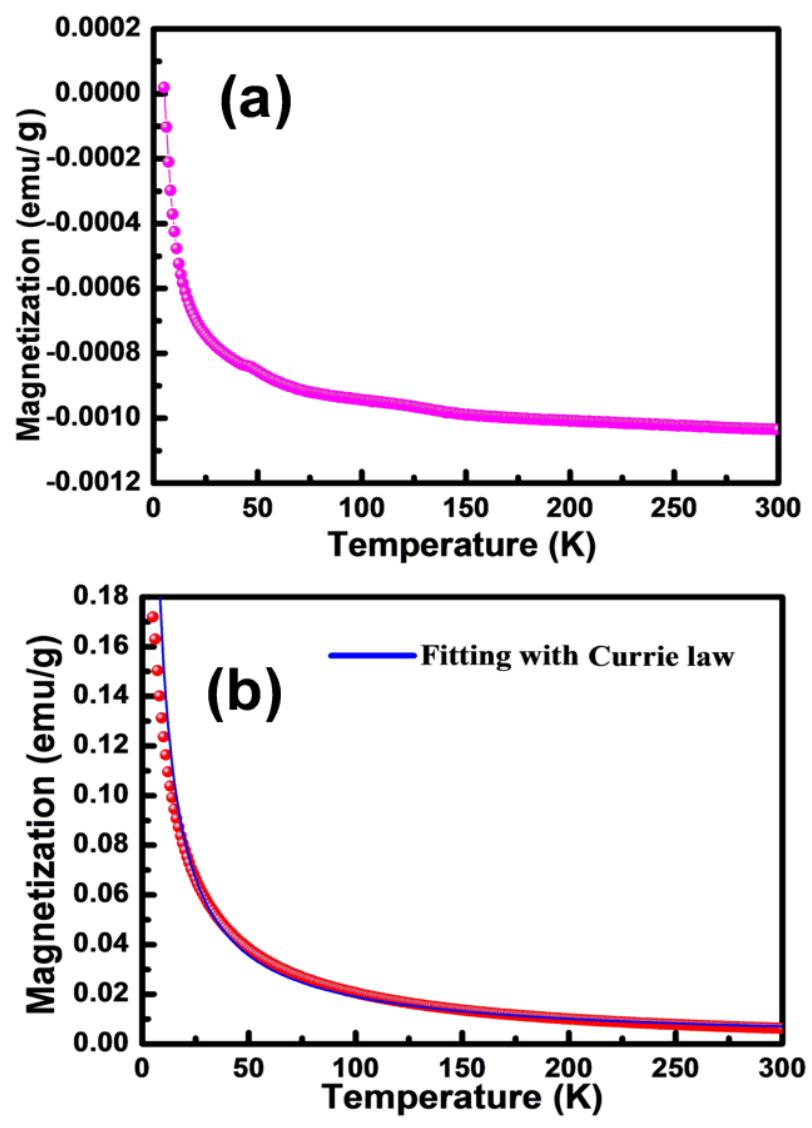

Fig. 16. Magnetization vs. temperature plot of (a) Nio nanocrystals and (b) Nit nanocrystals (with fitting) at fixed field of 1000 Oe 
Figures

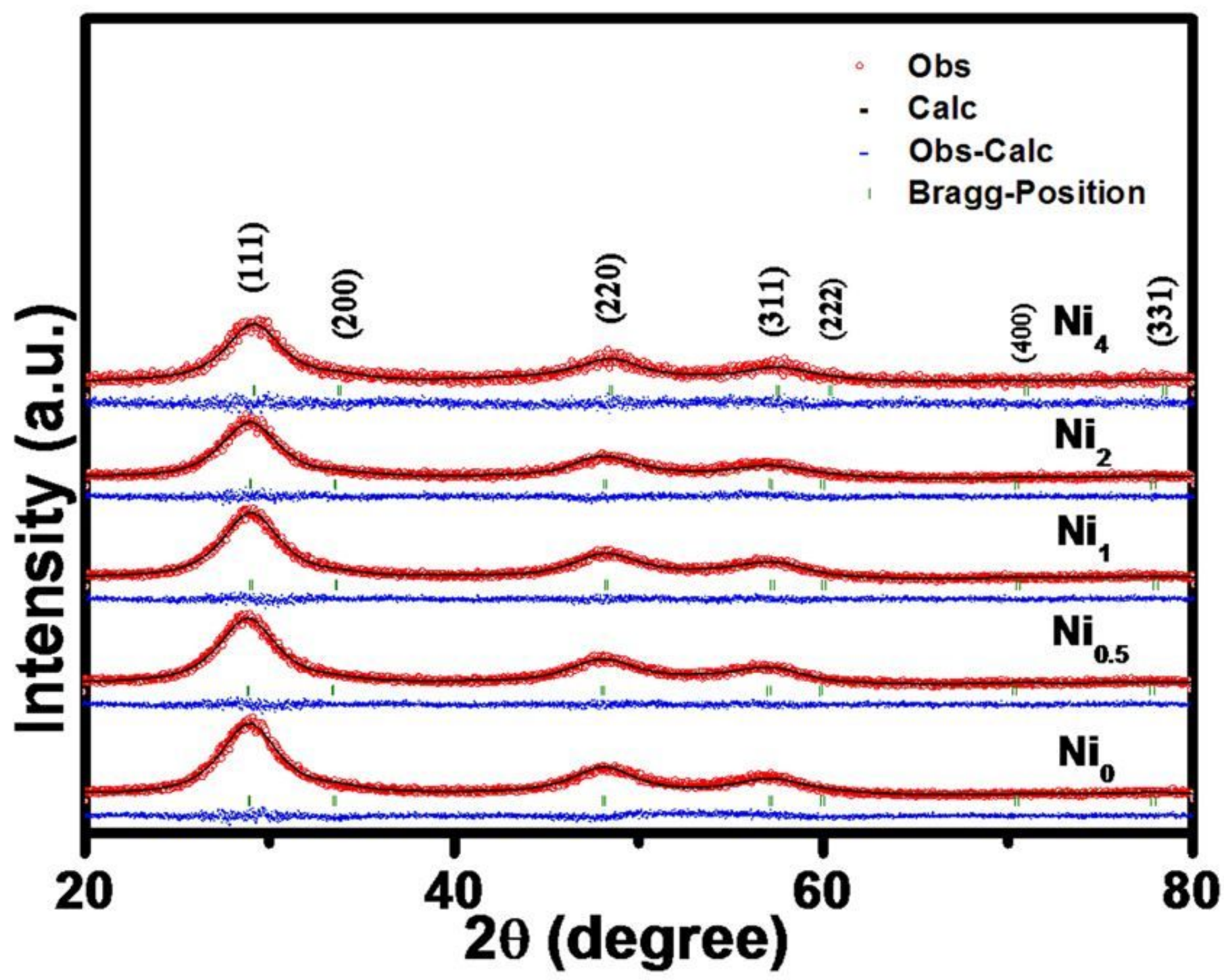

Figure 1

X-ray diffraction data of Zn1-x NixS $(0 \leq x \leq 0.04)$ nanocrystals with Rietveld refinement 

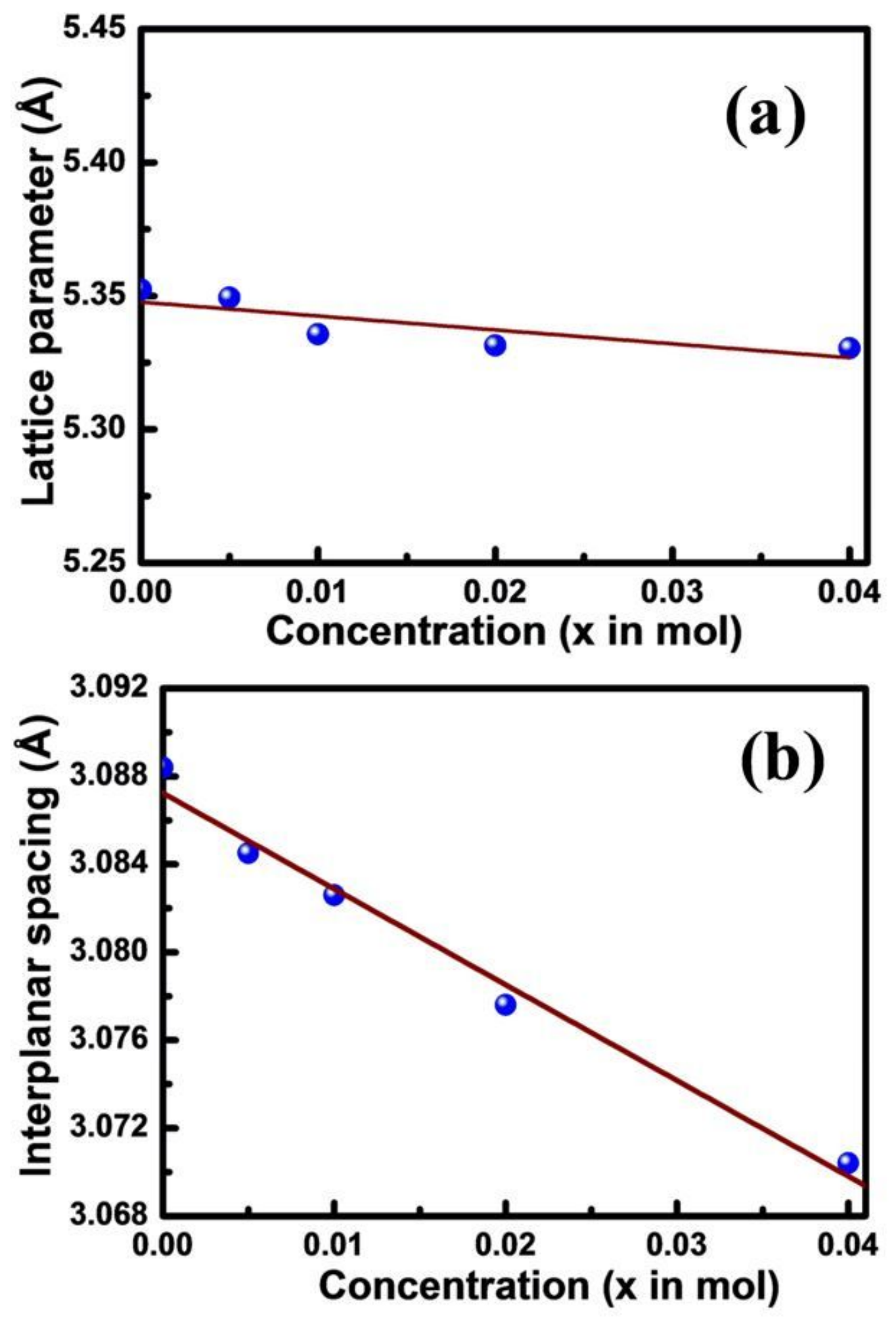

Figure 2

Change in (a) lattice parameter and (b) (111) inter-planar spacing of Zn1-x NixS ( $0 \leq x \leq 0.04)$ nanocrystals obtained from Rietveld refinement 

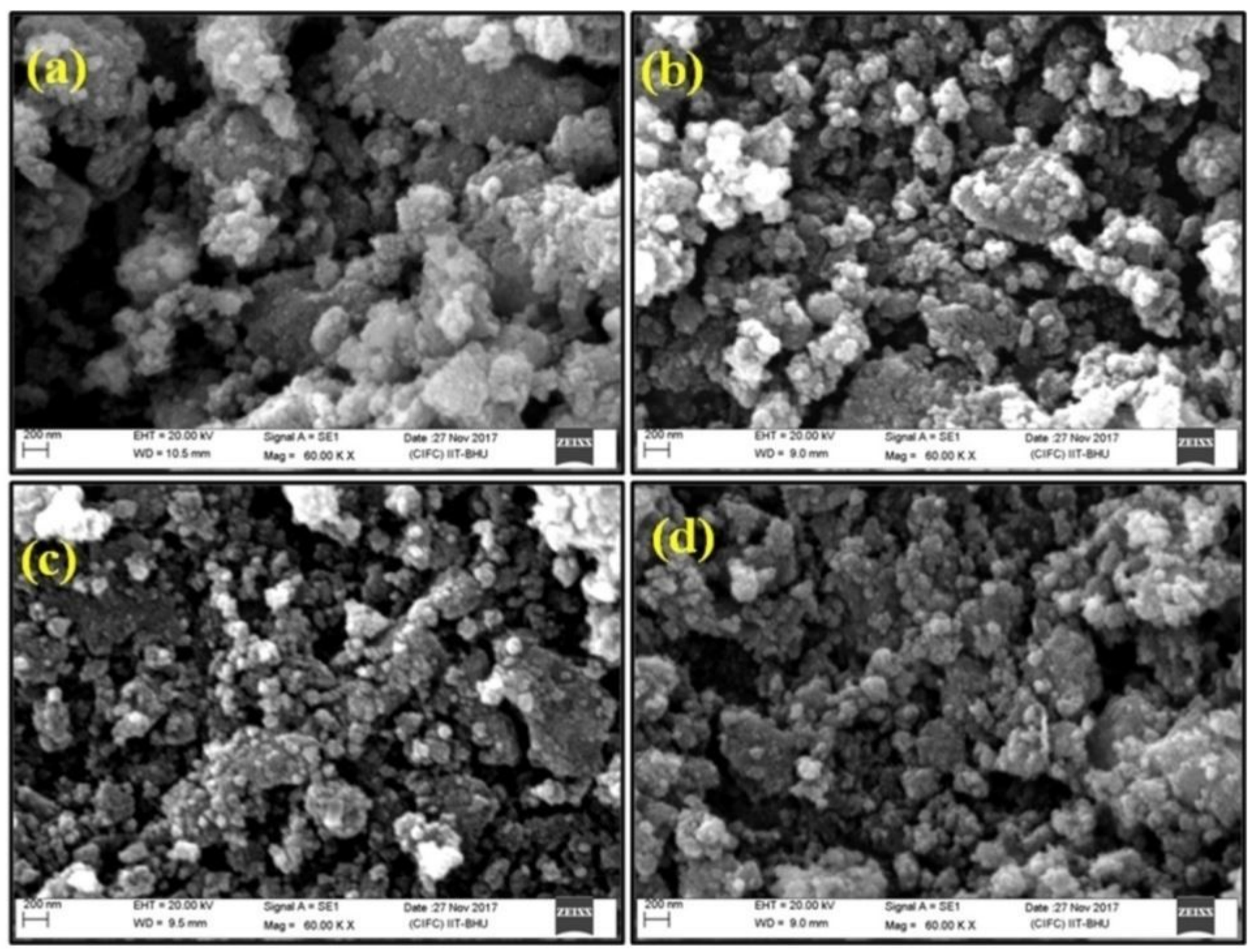

Figure 3

The SEM images of (a) NiO, (b) Ni1,(c) Ni2 and (d) Ni4 nanocrystals (magnification fixed at $60 \mathrm{KX}$ ) 


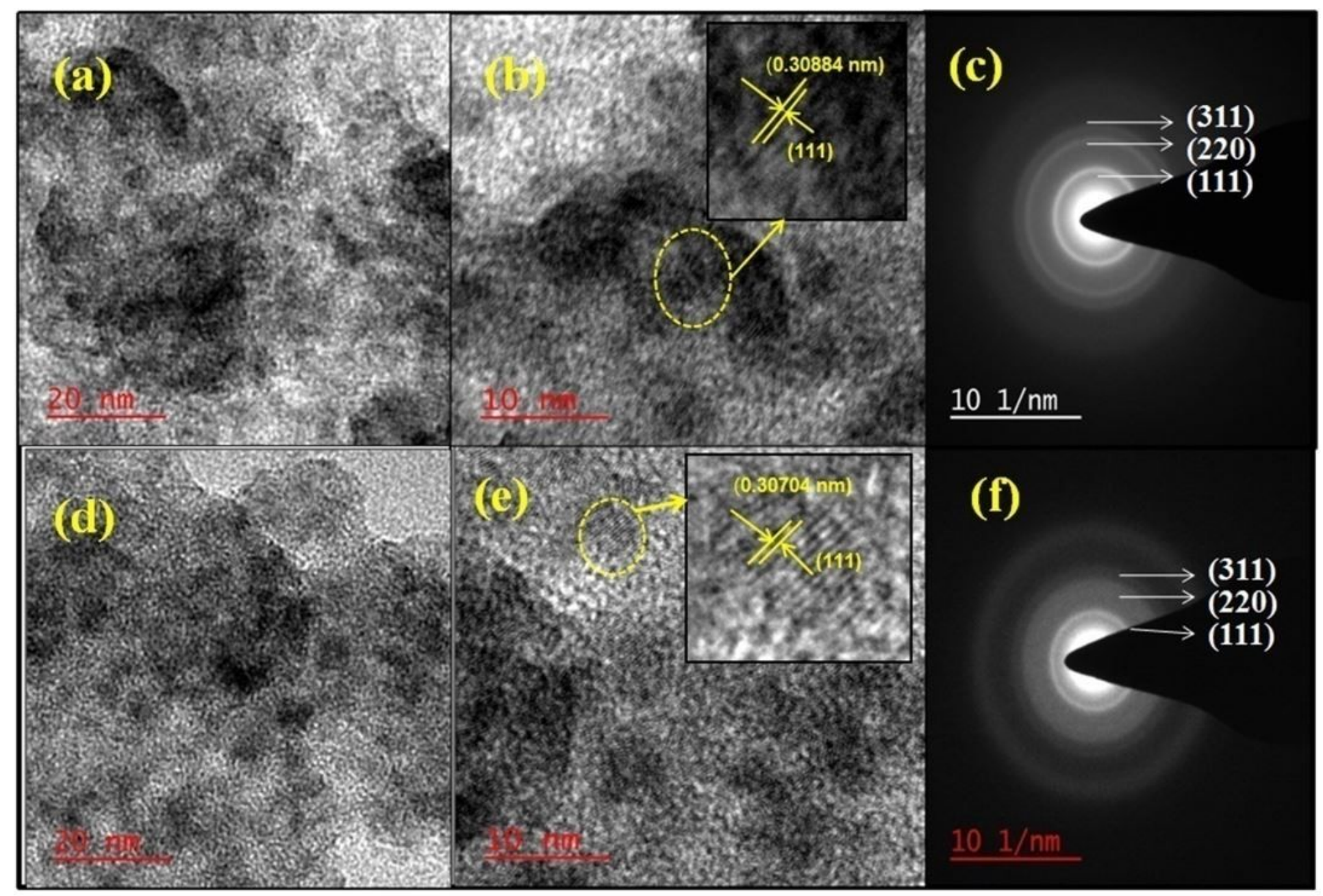

Figure 4

(a), (b) and (c) demonstrated low magnification TEM, HRTEM and SAED images of NiO nanocrystals respectively; (d), (e) and (f) showed low magnification TEM, HRTEM and SAED images of Ni4 nanocrystals respectively 


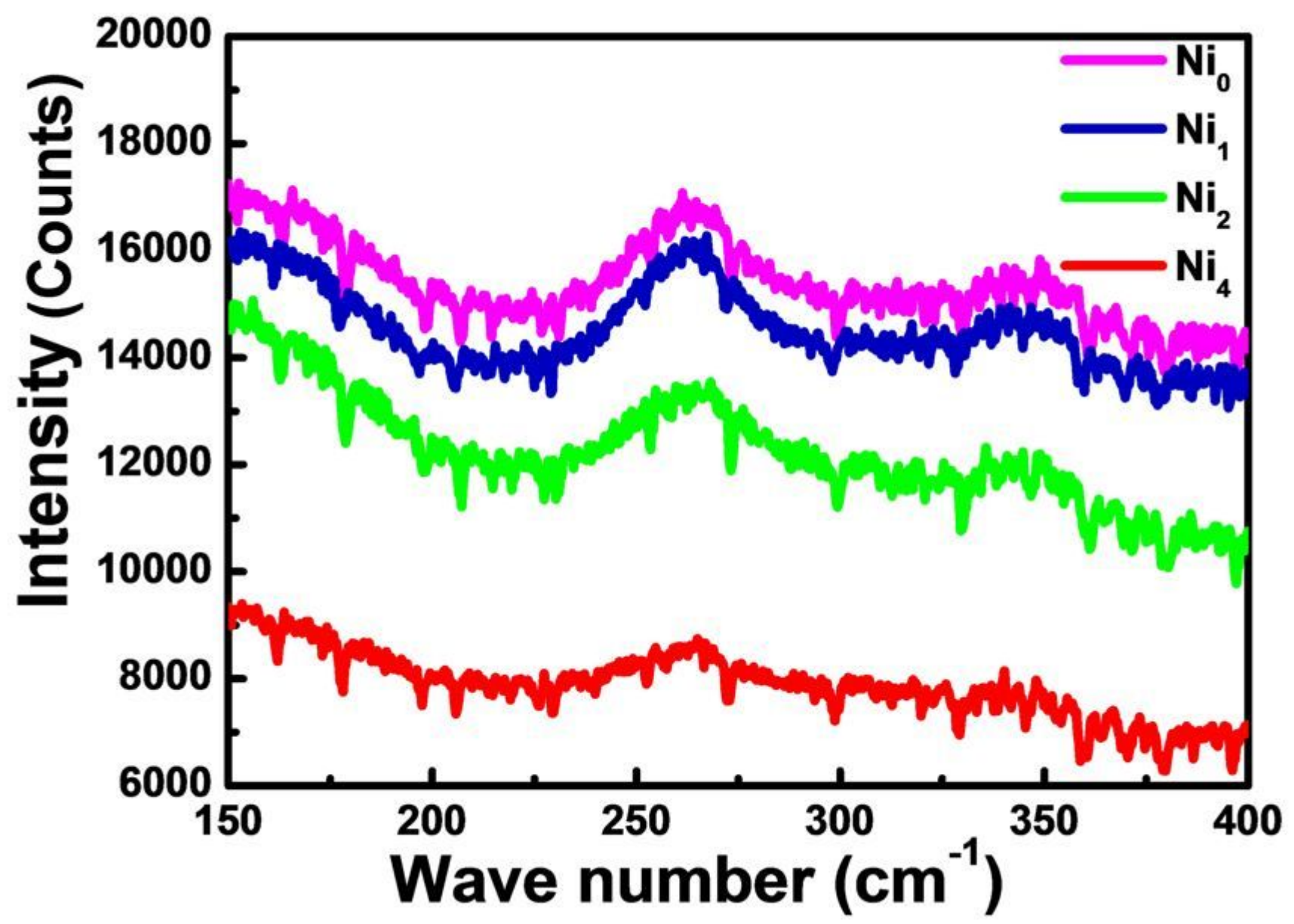

Figure 5

Raman spectrum of the Zn1-x NixS $(0 \leq x \leq 0.04)$ NCs observed at room temperature excited with wavelength $632.81 \mathrm{~nm}$ 


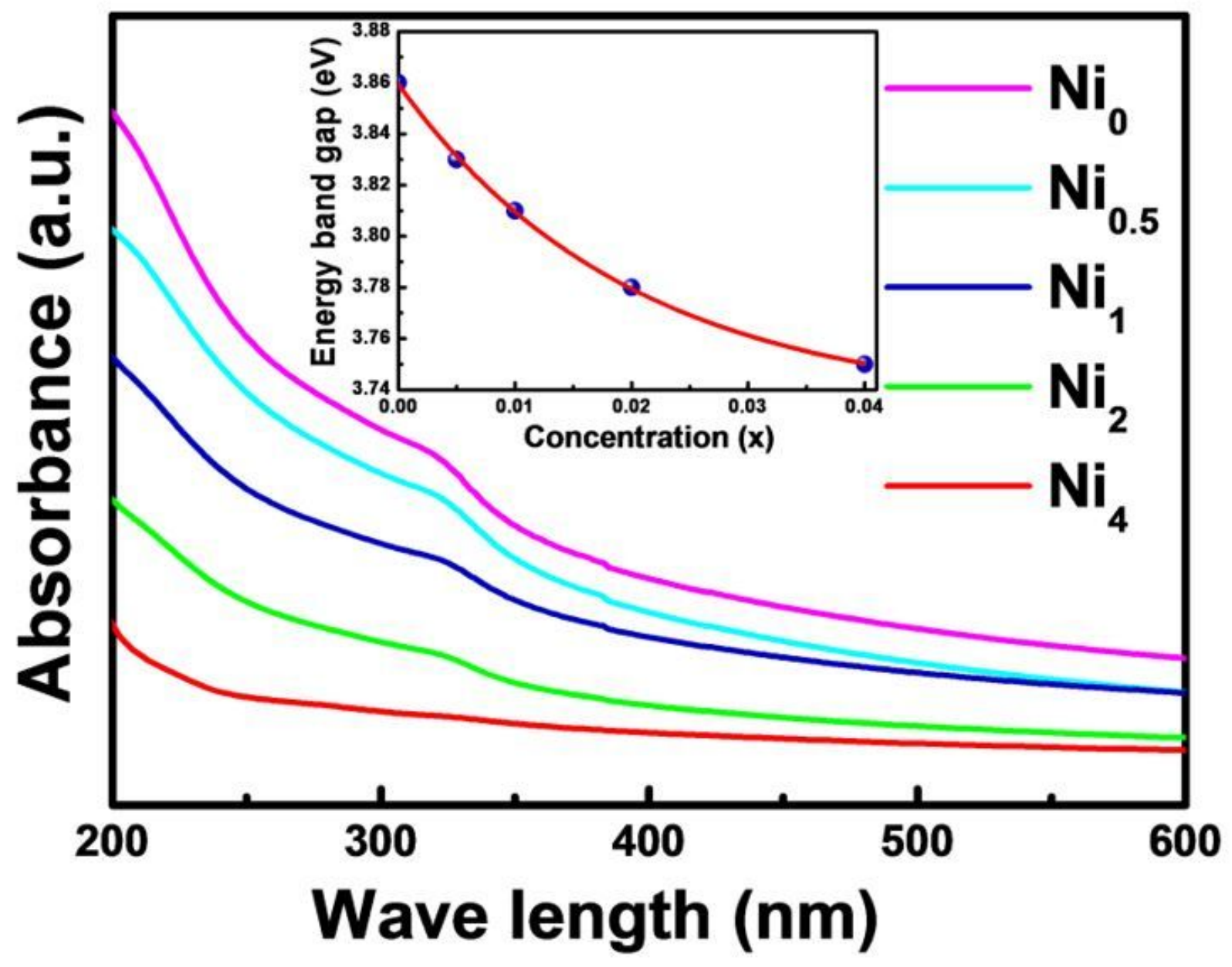

Figure 6

The UV-visible absorption spectrum of Zn1-x NixS $(0 \leq x \leq 0.04)$ nanocrystals and inset plot shows change of energy band gap of prepared samples 


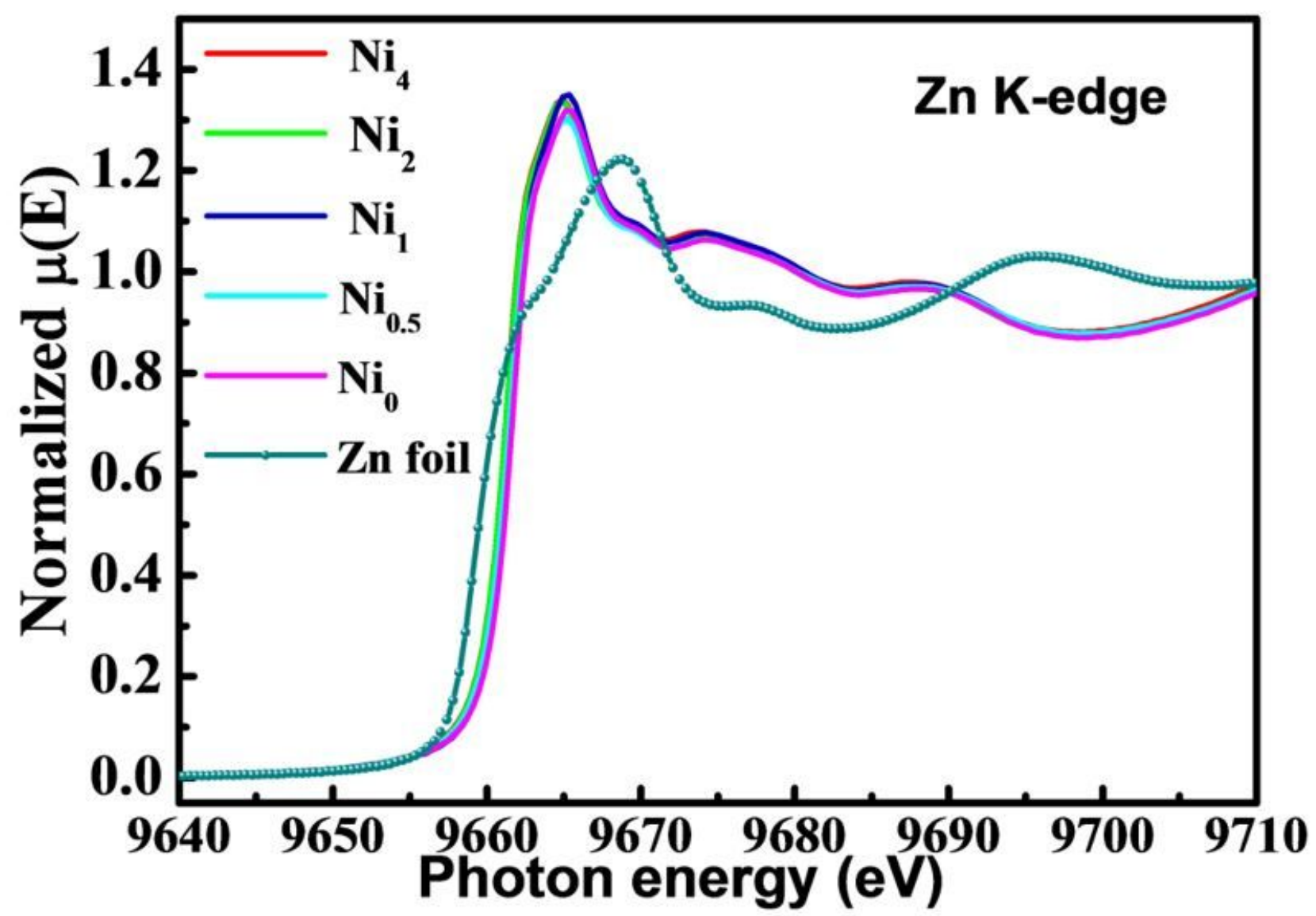

Figure 7

The normalized XANES data of the Zn1-x NixS $(0 \leq x \leq 0.04)$ nanocrystals observed at Zn K-edge 


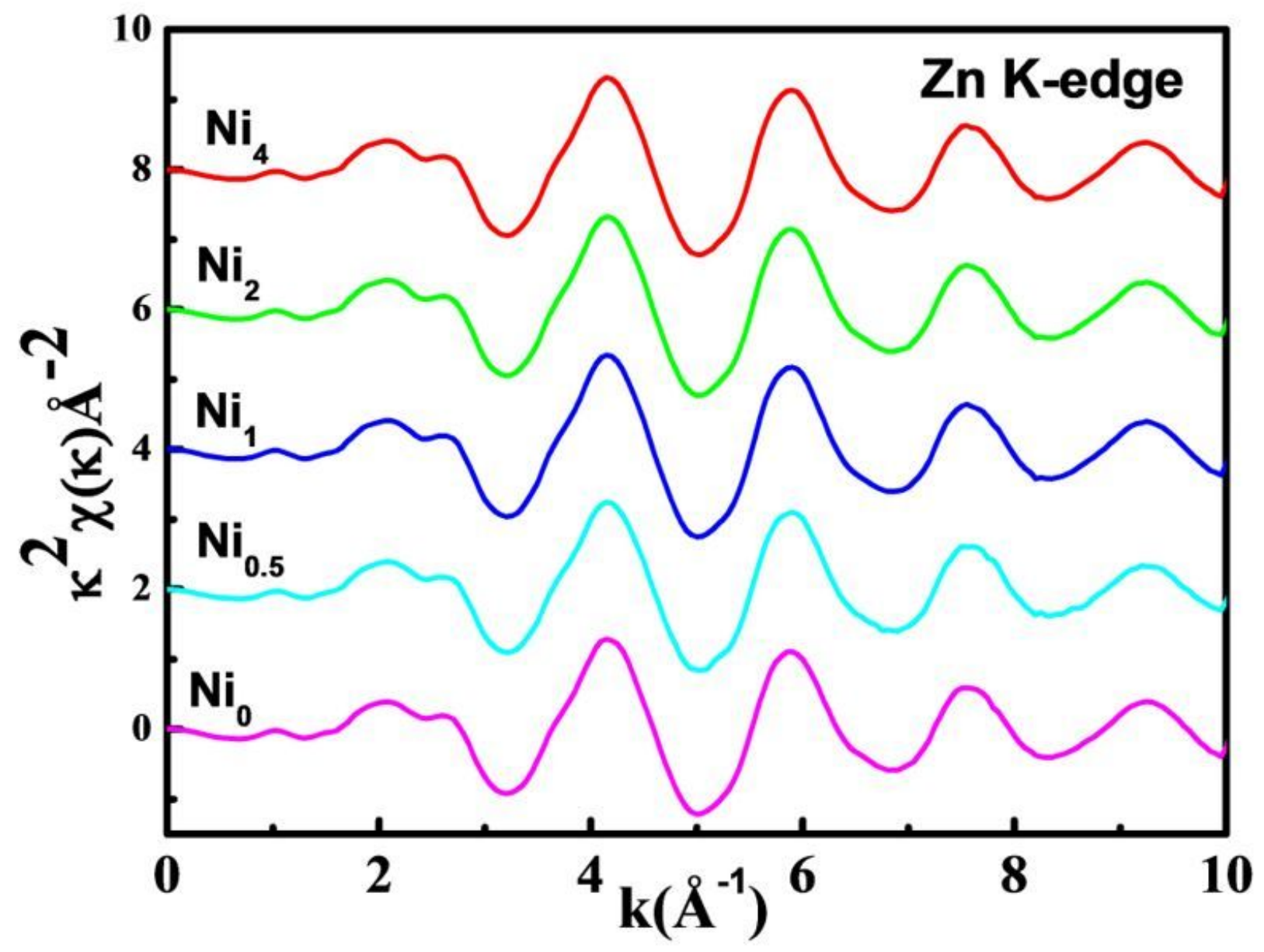

Figure 8

The K2 weighted X(k) spectra obtained at Zn K-edge of the Zn1-x NixS $(0 \leq x \leq 0.04)$ nanocrystals 

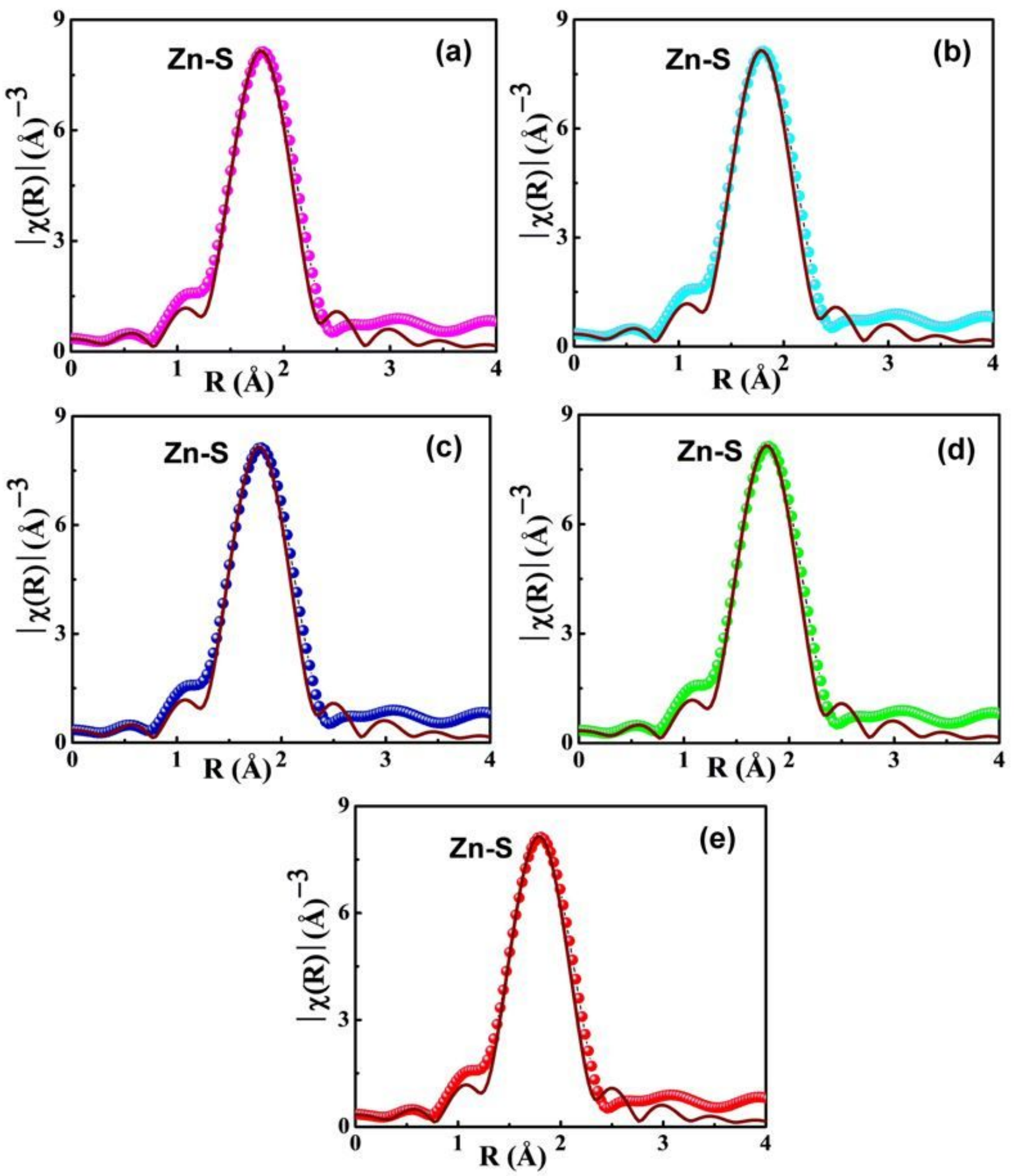

Figure 9

The best fitted experimental vs. data with theoretically created plot (showed in solid line) at Zn K-edge of (a) NiO, (b) Ni0.5, (c) Ni1, (d) Ni2 and (e) Ni4 nanocrystals 


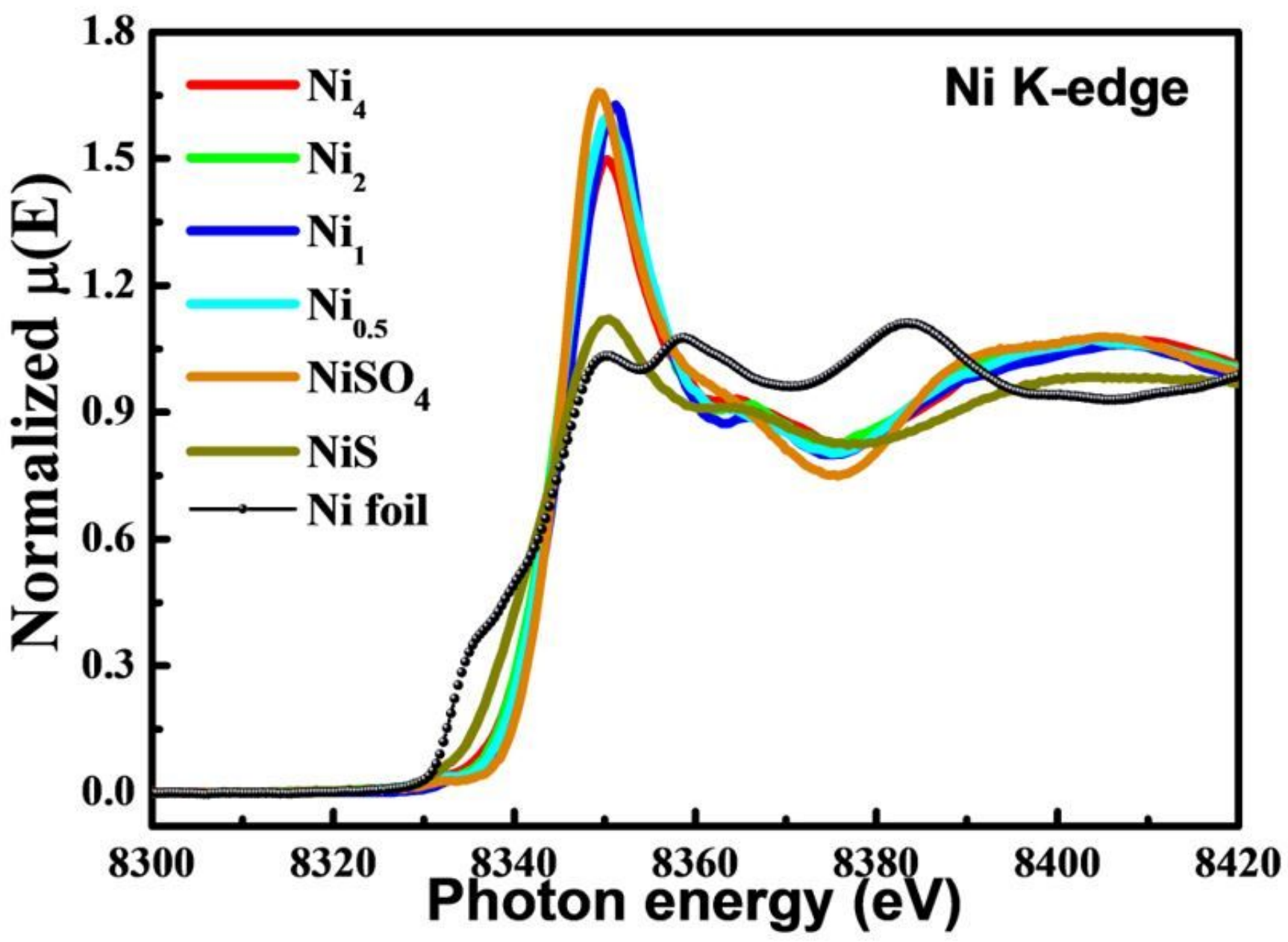

Figure 10

The normalized XANES data observed at Ni K-edge of the Zn1-x NixS nanocrystals 


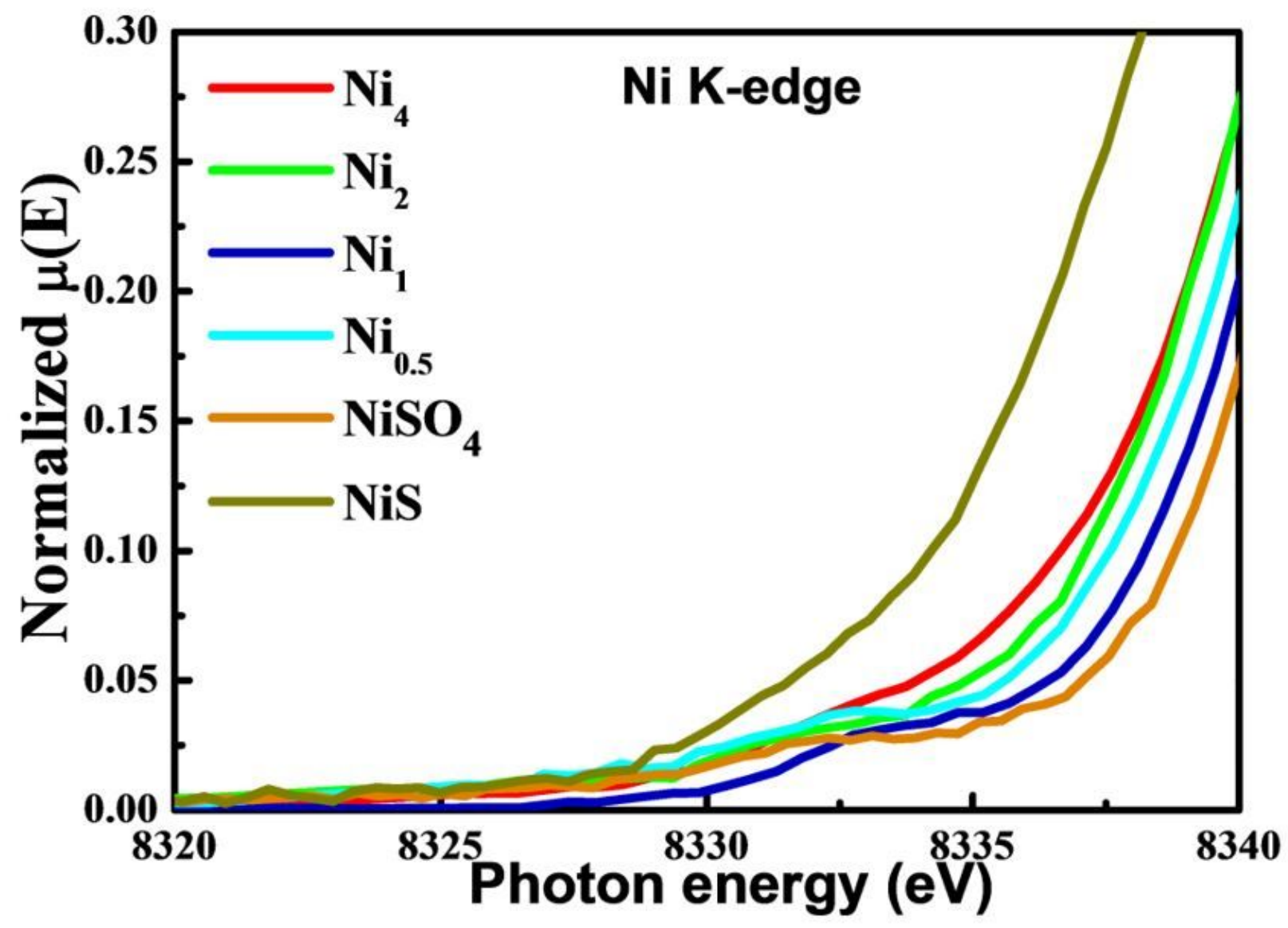

Figure 11

The pre-edge characteristic of the nickel doped ZnS NCs with reference to NiS and NiSO4 samples at $\mathrm{Ni}$ K-edge 


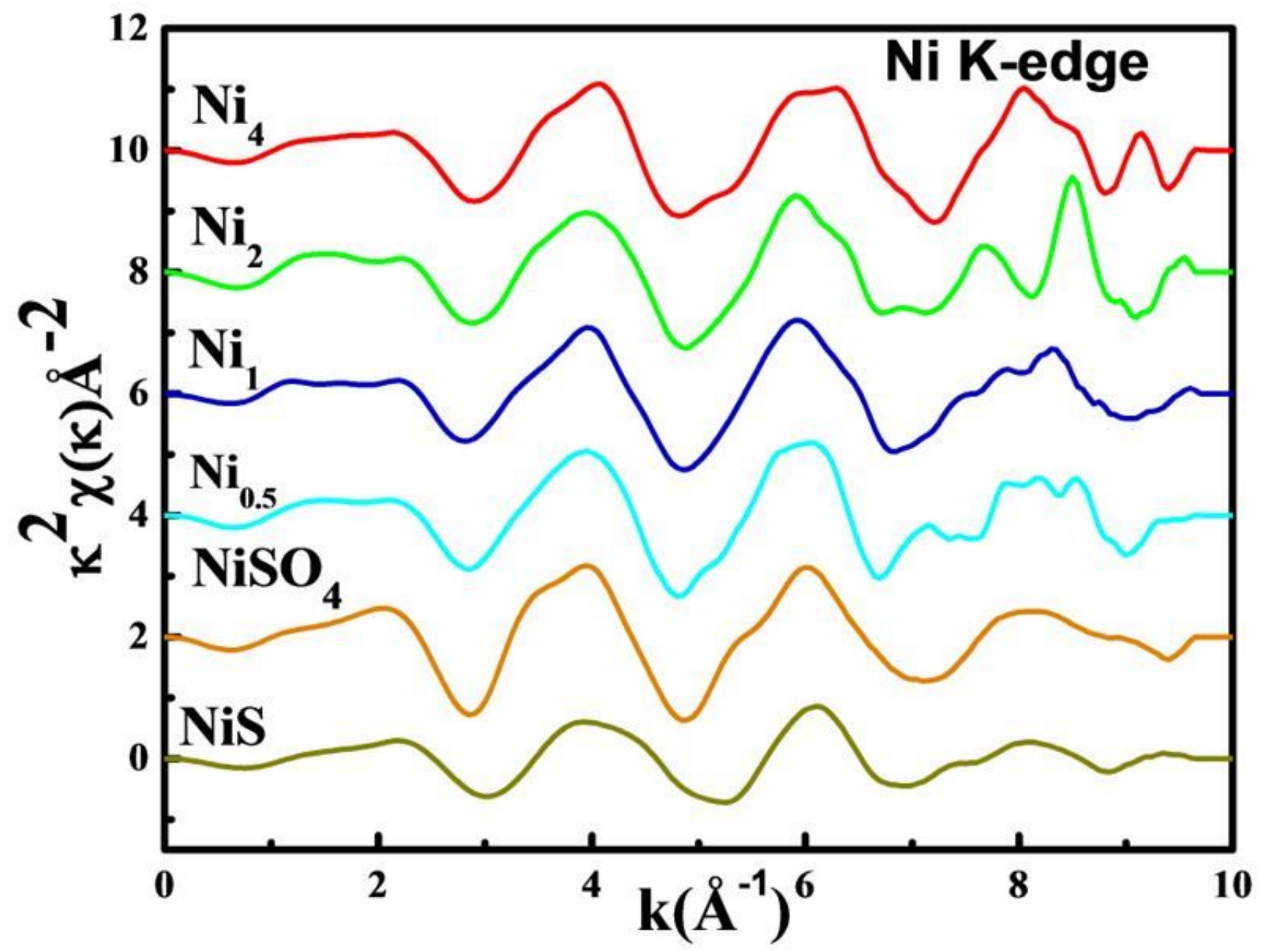

Figure 12

The K2 weighted X(k) spectra obtained at Ni K-edge of the Zn1-x NixS nanocrystals 


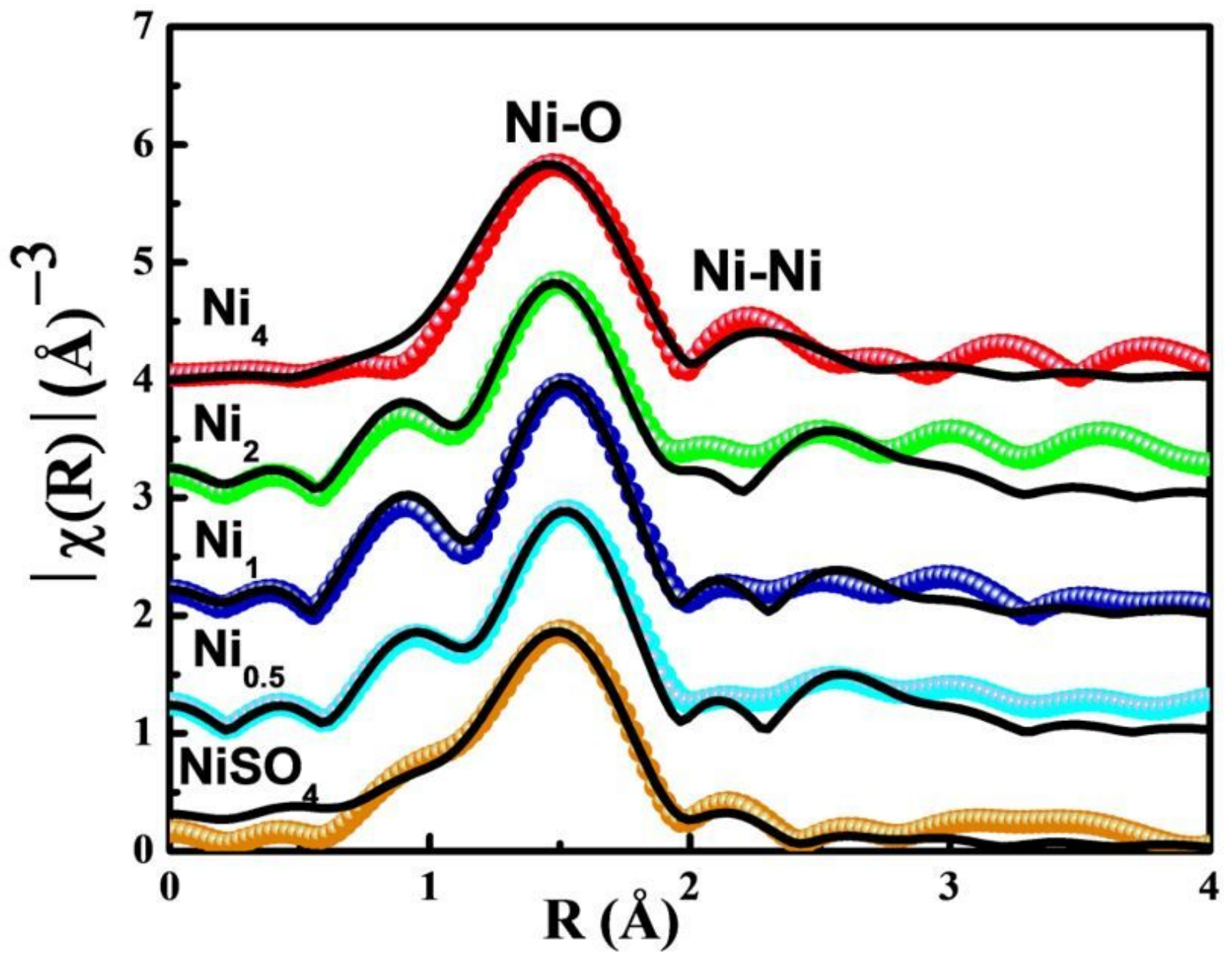

Figure 13

The best fitted experimental $X(R)$ vs. $R$ data with theoretically created data (showed in solid line) at Ni Kedge of the Zn1-x NixS nanocrystals 


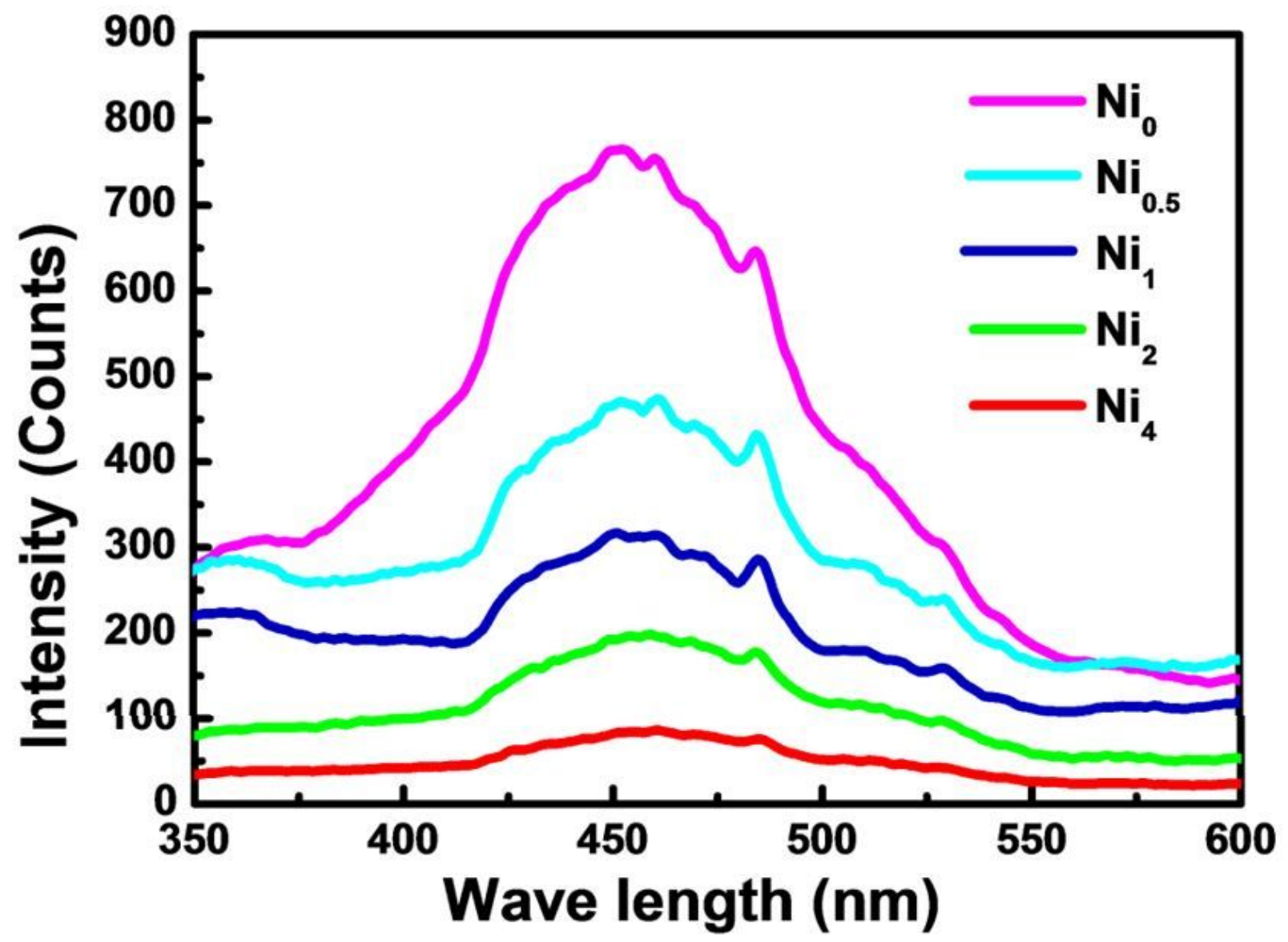

Figure 14

The photoluminescence spectrum of Zn1-x NixS $(0 \leq x \leq 0.04)$ nanocrystals observed by exciting at 320 $\mathrm{nm}$ 


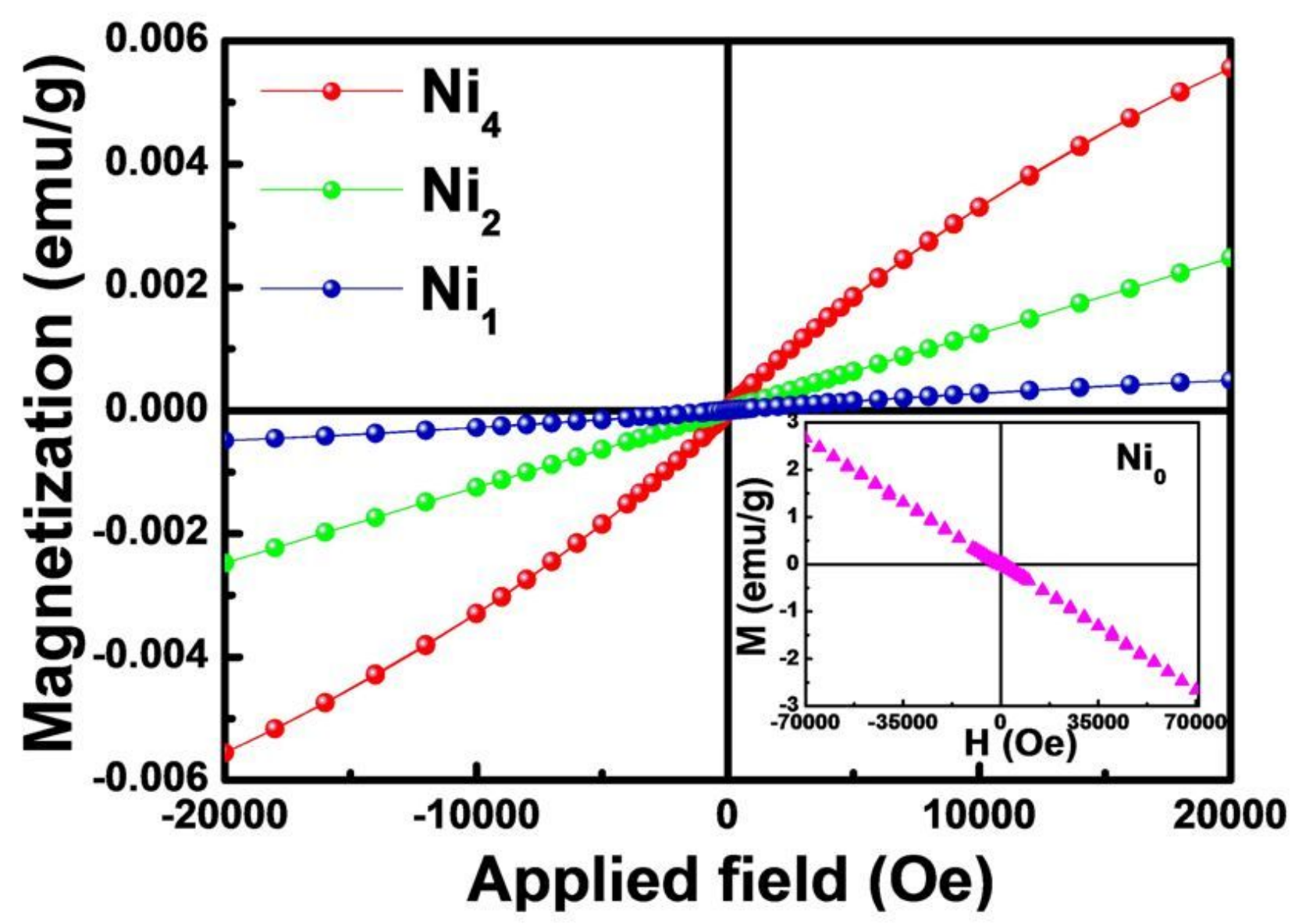

Figure 15

Magnetization vs. applied field measured in the range of \pm 20000 Oe at $300 \mathrm{~K}$ of Ni1, Ni2, Ni4 nanocrystals samples and the inset is the magnetization of $\mathrm{NiO}$ nanocrystals observed in the range of \pm 70000 Oe at $300 \mathrm{~K}$ 

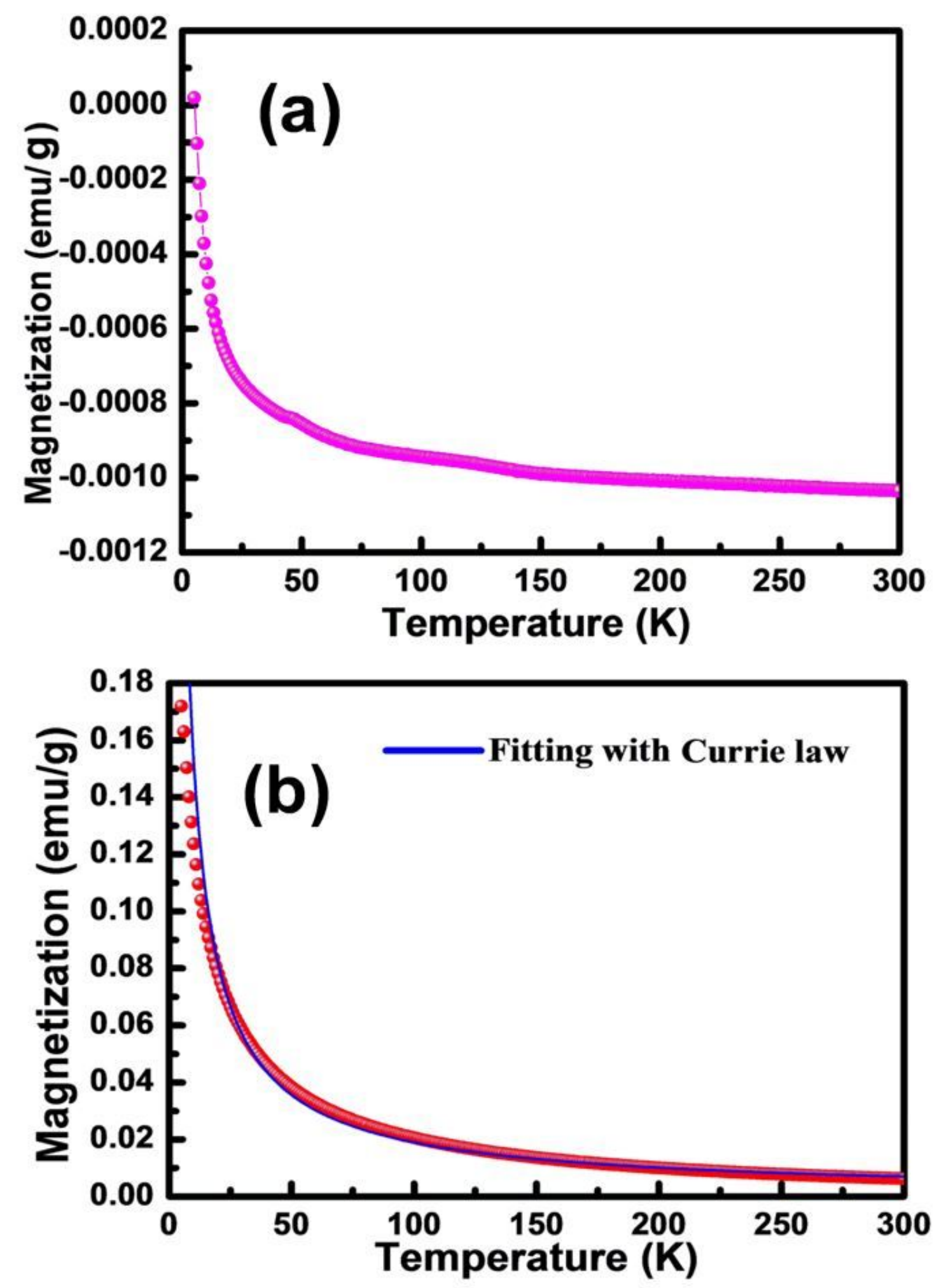

Figure 16

Magnetization vs. temperature plot of (a) NiO nanocrystals and (b) Ni4 nanocrystals (with fitting) at fixed field of $1000 \mathrm{Oe}$ 